ISSN: 0514-7336

DOI: http://dx.doi.org/10.14201/zephyrus2014741539

\title{
EL ARTE RUPESTRE ESQUEMÁTICO DEL ARROYO BARBAÓN (PARQUE NACIONAL DE MONFRAGÜE, CÁCERES): CONTEXTUALIZACIÓN ARQUEOLÓGICA Y CARACTERIZACIÓN DE PIGMENTOS
}

\section{Schematic Rock Art in Arroyo Barbaón (Monfragüe National Park, Cáceres): Archaeological contextualization and pigments characterization}

Hipólito Collado Giraldo*,**, Pierluigi Rosina*, José Julio García Arranz***, Hugo Gomes*, Luis F. Da Silva Nobre**, Isabel M. Domínguez García**, David Duque Espino****, José M.a Fernández VAldés*****, Emilia Blasco Laffón ${ }^{* * * * *}$, José M. a Torrado Cárdeno**, Lázaro Rodríguez Dorado**, Esther Rivera Rubio**, Magdalena Nacarino de los Santos**, José Enrique Capilla Nicolás** y Samuel PÉREZ RoMero**

* Grupo de Investigación "Quaternário e Pré-História"/Grupo de Investigación CUPARQ.

** ACINEP. Instituto de Estudios Prehistóricos/CEMAC. Centro de Estudios Evolución, Medio Ambiente y Cultura

*** Área de Historia del Arte. Facultad de Filosofía y Letras-UEX. Campus Universitario. Avda. de la Universidad, s/n.10004 Cáceres. Correo-e: hipolitocollado@gmail.com

**** Área de Prehistoria. Facultad de Filosofía y Letras-UEX. Campus Universitario. Avda. de la Universidad, s/n. 10004 Cáceres

***** Univ. Politécnica de Madrid. Cl Ramiro de Maeztu, 7. 28040 Madrid

Recepción: 4/09/2013; Revisión: 26/02/2014; Aceptación: 23/03/2014

BIBLID [0514-7336 (2014) LXXIV, julio-diciembre; 15-39]

\begin{abstract}
Resumen: El Parque Nacional de Monfragüe (Cáceres) conserva un importante complejo de arte rupestre formado por más de un centenar de abrigos con pinturas y grabados postpaleolíticos. En el presente trabajo vamos a dar a conocer un avance de las conclusiones obtenidas en las últimas campańas de investigación llevadas a cabo en el sector del cañón del Arroyo Barbaón (Serradilla). En él se ha procedido a la documentación digital de las representaciones pictográficas de sus 29 abrigos. Además, a través de las excavaciones realizadas en el interior de la Cueva del Sapo, que han proporcionado diversos materiales cerámicos y líticos, así como los restos de un hogar, se intenta contextualizar arqueológicamente el conjunto de arte rupestre. Finalmente, el hallazgo en el abrigo Friso del Terror de un fragmento de cuarcita desprendido que conservaba algunos trazos pintados ha permitido realizar análisis para caracterizar el pigmento que fue utilizado en su elaboración. Con estas aportaciones pretendemos una aproximación más precisa a cuestiones como las técnicas de realización, cronología y funcionalidad de la pintura esquemática en este espacio natural cacereño.

Palabras clave: Pintura esquemática; Funcionalidad del arte rupestre; Arqueometría; Técnicas pictóricas; Microfluorescencia-X; Espectroscopia Raman; Microestratigrafía.
\end{abstract}

Aвstract: Monfragüe National Park (Cáceres) preserved a very important schematic rock art complex with more than a hundred shelters with postpalaeolithic paintings and engravings. In this paper we'll provide

(C) Universidad de Salamanca

Zephyrus, LXXIV, julio-diciembre 2014, 15-39 
an advance of our last research campaigns conclusions carried out in the Arroyo Barbaón sector (Serradilla). We have proceeded to the digital documentation of 29 rock art shelter figures. Furthermore, through the archaeological excavation inside Cueva del Sapo, which have provided some pottery fragments and stone tools as well as bonfire remains, we try to get the archaeological context for the rock art complex. Finally, the finding of a small detached fragment with some traces in red in the Friso del Terror shelter, has allowed the analysis to characterize the pigment that was used. The goal was to provide accurate information about technical issues, chronology and functionality of schematic rock art in this natural park in Cáceres province.

Key words: Schematic painting; Functionality of the Rock art; Archaeometry; Painting techniques; Microfluorescence; Raman Spectroscopy; Micro-Stratigraphy.

\section{Introducción: la investigación en torno al patrimonio cultural en el Parque Nacional de Monfragüe (Cáceres) ${ }^{1}$}

Desde el año 1996 un equipo de investigadores, coordinado desde la Dirección General de Patrimonio Cultural del Gobierno de Extremadura y el Dpto. de Arte y Ciencias del Territorio de la Univ. de Extremadura, en colaboración con el Instituto de Estudios Prehistóricos, y al que se ha incorporado en fechas más recientes el Grupo de Investigación Quaternário e Pré-História del Centro de Geociências (Portugal), técnicos de la Universidad Politécnica de Madrid y miembros del Área de Prehistoria de la universidad extremeña, viene desa-rrollando trabajos de localización, inventario, estudio y valorización del patrimonio cultural localizado en el Parque Nacional de Monfragüe (Cáceres) en todas sus posibles vertientes:

${ }^{1}$ El presente trabajo se inscribe dentro del Proyecto de Investigación de la Dirección General de Patrimonio Cultural de la Consejería de Educación y Cultura de la Junta de Extremadura, titulado "Estudios de lugares con arte rupestre al aire libre en el Arroyo Barbaón (término municipal de Serradilla, Cáceres)" (Exp.: INT/2011/143 YAC82987), coordinado por H. Collado Giraldo y J. J. García Arranz, desarrollado entre octubre y diciembre de 2011. Los análisis arqueométricos han sido realizados en el marco del proyecto titulado RUPSCIENCE - PTDC/HIS-ARQ/101299/2008 Analysis of the operational chains, archaeometry and chronology of Rock Art Paintings. An approach to materials technology of Portugal, Spain and Colombia's contexts, cuyo investigador principal es H. Gomes, aprobado por la Fundação para a Ciência e Tecnologia, y cofinanciado con fondos Feder. La investigación fue llevada a cabo en el Instituto Politécnico de Tomar, el Centro de Interpretación Arqueológica del Alto Ribatejo, perteneciente al Grupo Quaternário e Pré-História del Centro de Geociências (Fundação para a Ciência e Tecnologia) (Grupo Quaternário e PréHistória). Queremos agradecer encarecidamente la amable colaboración prestada por L. Santos y G. Nash. histórico-artística, arqueológica, etnográfica, industrial y de obras de ingeniería.

A lo largo de estos tres lustros, gracias sobre todo a una intensa labor de campo, el avance de nuestro conocimiento sobre este variado conjunto de elementos patrimoniales ha sido notable. Sin embargo, ya desde las primeras campañas de prospección se puso de manifiesto que, de entre todos los bienes culturales preservados en este espacio natural, destaca sobre todos los demás por su amplia difusión, cantidad y calidad el llamativo complejo de estaciones con arte rupestre prehistórico que se localiza entre sus roquedos. Tales valores han elevado a Monfragüe al rango de uno de los conjuntos de referencia en el contexto del arte parietal esquemático de la Península Ibérica (Fig. 1).

La inusual densidad de las rocas pintadas en el ámbito del parque y el buen estado de conservación de muchas de sus pinturas, factores unidos a la singularidad temática y, sobre todo, a las evidentes relaciones existentes entre los patrones de distribución espacial y las características del entorno natural y geomorfológico que contextualiza a estas manifestaciones plásticas, han permitido plantear interpretaciones para el arte rupestre de este espacio natural vinculadas a la arqueología del paisaje, considerando en este sentido el valor de las manifestaciones prehistóricas en el marco de los procesos de apropiación y control simbólicos de los territorios (Collado y García Arranz, 2001; 2005: 11-50; 2007: 346-349).

A estas aportaciones hay que añadir, en fechas más recientes, el desarrollo de nuevas vías de aproximación al conocimiento de los diversos aspectos que convergen en el fenómeno del arte rupestre postpaleolítico occidental, y con este fin se ha puesto en marcha un programa de caracterización de los pigmentos con los que fueron realizadas aquellas pictografías. Se trata de una labor sistemática 


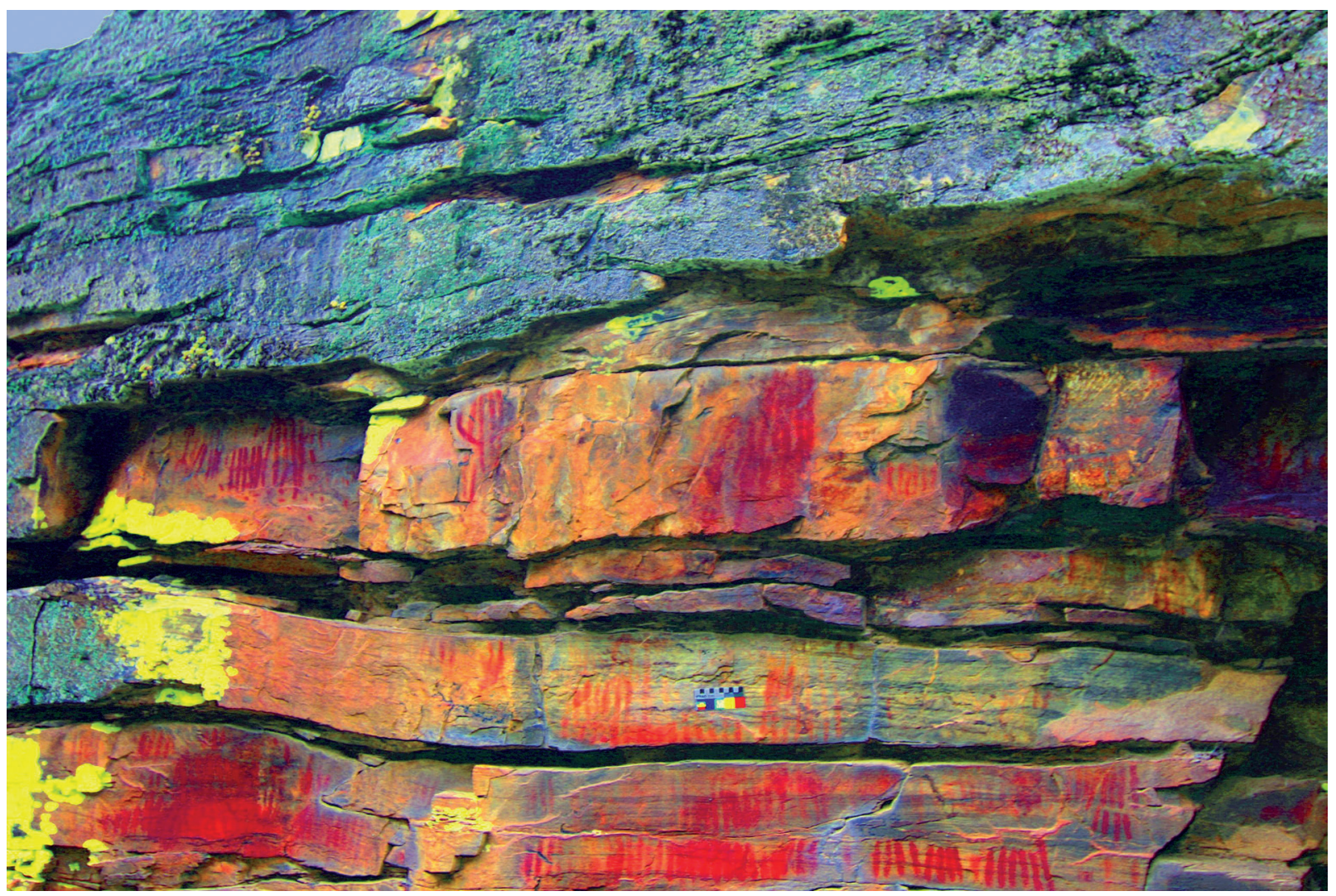

Fig. 1. Pinturas esquemáticas del Friso de las Barras (Arroyo Barbaón, Parque Nacional de Monfragüe); imagen tratada con Dstrech.

a medio plazo, que excede el ámbito territorial del Parque Nacional, pero cuyos primeros ensayos tuvieron lugar precisamente en el contexto de Monfragüe, y más concretamente en la Cueva del Castillo (Torrejón el Rubio), con ocasión de los trabajos que se llevaron a cabo para la adecuación a la visita pública de esta notable estación (Collado y García Arranz, 2007: 318-320). Ya en estas actuaciones se evidenció que era esencial la colaboración de un equipo multidisciplinar de especialistas, en cuya labor resultaron de especial interés, precisamente, los análisis de pigmentos llevados a cabo por los miembros del Grupo de Investigación "Quaternário e Pré-História". La continuidad de esta colaboración es la que ha permitido que, en los últimos meses de 2011, se desarrollaran diversos trabajos arqueológicos centrados en el conjunto de arte rupestre localizado en el sector del Arroyo Barbaón, también perteneciente al ámbito geográfico del Parque de Monfragüe, y cuyas conclusiones presentamos, a modo de avance, en las siguientes páginas.

\section{Características generales del arte rupestre en el Parque Nacional de Monfragüe}

Este importante espacio natural protegido de la Comunidad Autónoma de Extremadura se sitúa en el área centro-oriental de la provincia de Cáceres, en el punto intermedio de un imaginario triángulo trazado entre las localidades de Navalmoral de la Mata, Plasencia y Trujillo. Su actual extensión de 17852 ha incluye los términos municipales de Serradilla, Serrejón, Torrejón el Rubio, Casas de Miravete, Jaraicejo, Toril y Malpartida de Plasencia. Ha sido declarado por el Gobierno de Espańa como Parque Nacional -marzo de 2007-, y reconocido a nivel internacional como Reserva Mundial de la 
Biosfera por la unESCO -en julio de 2003-, y, hoy por hoy, constituye uno de los enclaves más representativos del bosque y matorral mediterráneos de la Península Ibérica gracias a su marcada evolución ecológica. Sus diversos ecosistemas, que encierran el $80 \%$ de la fauna protegida de España y que constituyen un ámbito esencial para la conservación y mantenimiento de la biodiversidad a escala global, sirven de refugio a unas 290 especies de vertebrados, erigiéndose de este modo en la reserva más importante de Europa en lo que se refiere a especies en peligro de extinción, entre las que se pueden destacar el buitre negro, el águila imperial ibérica, el alimoche, la cigüeña negra o el lince ibérico, además de diversas variedades de reptiles y anfibios (Gumiel et al., 2008: 9-10; Leco et al., 2009: 58 y ss.).

Desde un punto de vista geomorfológico, este espacio natural se sitúa en la zona central del Macizo Hespérico Ibérico, geológicamente caracterizado por grandes afloramientos de materiales pertenecientes al Cámbrico inferior, sobre los que se disponen, de forma discordante, materiales postcámbricos-Ordovícico y Silúrico-, y los correspondientes a la cobertera cenozoica; todo ello resultó fuertemente deformado y afectado por las orogenias finiCadomiense, Hercínica y Alpina (Gumiel et al., 2008: 13 y ss.). El resultado geomorfológico de estos procesos es una serie de apretadas alineaciones de cerros y valles que se disponen alargados y curvados en dirección ONO-ESE, dando lugar a un relieve de tipo apalachense que caracteriza el sinforme de Monfragüe, estructura tectónica formada durante la orogenia hercínica, en la que se han encajado profundamente durante el cuaternario los principales cauces fluviales (Gumiel et al., 2008: 52 y 54). El río Tajo, que recorre el parque longitudinalmente, configura, junto a su afluente principal el río Tiétar y otros cauces menores como los arroyos Barbaón, Calzones o Malvecino, una extensa red hidrográfica que articula este espacio geográfico, al abrir auténticos 'corredores' o vías de paso por donde resulta posible salvar la serie de elevaciones cuarcíticas, de entre 600 y 850 m.s.n.m., que flanquean sus cauces -sierras de Mohedas, Piatones, La Canaleja, Las Corchuelas, Santa Catalina...-. Es en estas formaciones serranas, que conforman una importante barrera natural entre la penillanura central cacereña y las tierras altas del NE de Cáceres, y concretamente en los abrigos y oquedades rocosas conformadas por erosión diferencial en la base de sus afloramientos cuarcíticos, donde se ubican, por regla general, las estaciones decoradas con pinturas esquemáticas.

Hasta la fecha, se ha localizado en el área del Parque Nacional y su entorno inmediato un total de 109 enclaves con pinturas o grabados esquemáticos, que se distribuyen a todo lo largo y ancho de su territorio (Fig. 2). Este conjunto de abrigos ha sido estructurado, de acuerdo con criterios de carácter estrictamente geográfico, en 13 sectores, sin descartar la posibilidad de que, con el desarrollo de nuevos trabajos de prospección o el reconocimiento más detenido de áreas que hasta el momento no han sido bien revisadas o se han inspeccionado con poca intensidad -Navacalera, La Parrilla o la Portilla del Tiétar-, se pueda incrementar esta cifra:

- Sector de la sierra de Santa Catalina -término de Serradilla-, en el tramo comprendido entre la localidad de Serradilla y Peña Falcón. Por razones orográficas esta zona se ha subdividido en dos áreas más reducidas: la primera de ellas situada entre el Collado del abrigo del Pectisol y el Risco de la Cueva, con 20 estaciones, y una segunda, que incluye la alineación serrana que se extiende entre la garganta del Arroyo del Helechal y Peña Falcón, que reúne otros 19 abrigos decorados.

- Sector del Arroyo Barbaón -término de Serradilla-, que agrupa un complejo de 29 estaciones, localizadas fundamentalmente aguas abajo en el tramo conocido como la Portilla del Barbaón.

- Sector de la sierra del Mingazo -término de Serradilla-, con 2 estaciones.

- Sector del Puerto de la Serrana -término de Serradilla-, con 1 estación.

- Sector de la sierra de Monfragüe-Corchuelas -término de Torrejón el Rubio-, en el tramo comprendido desde el Salto del Gitano, en el río Tajo, hasta la altura del Palacio Viejo de Las Corchuelas: cuenta con 13 estaciones.

- Sector de la sierra de la Canaleja -término de Torrejón el Rubio-, localizado entre la sierra de Las Corchuelas y la sierra del Espejo, en la zona centro-meridional del parque. Este sector agrupa 5 estaciones. 


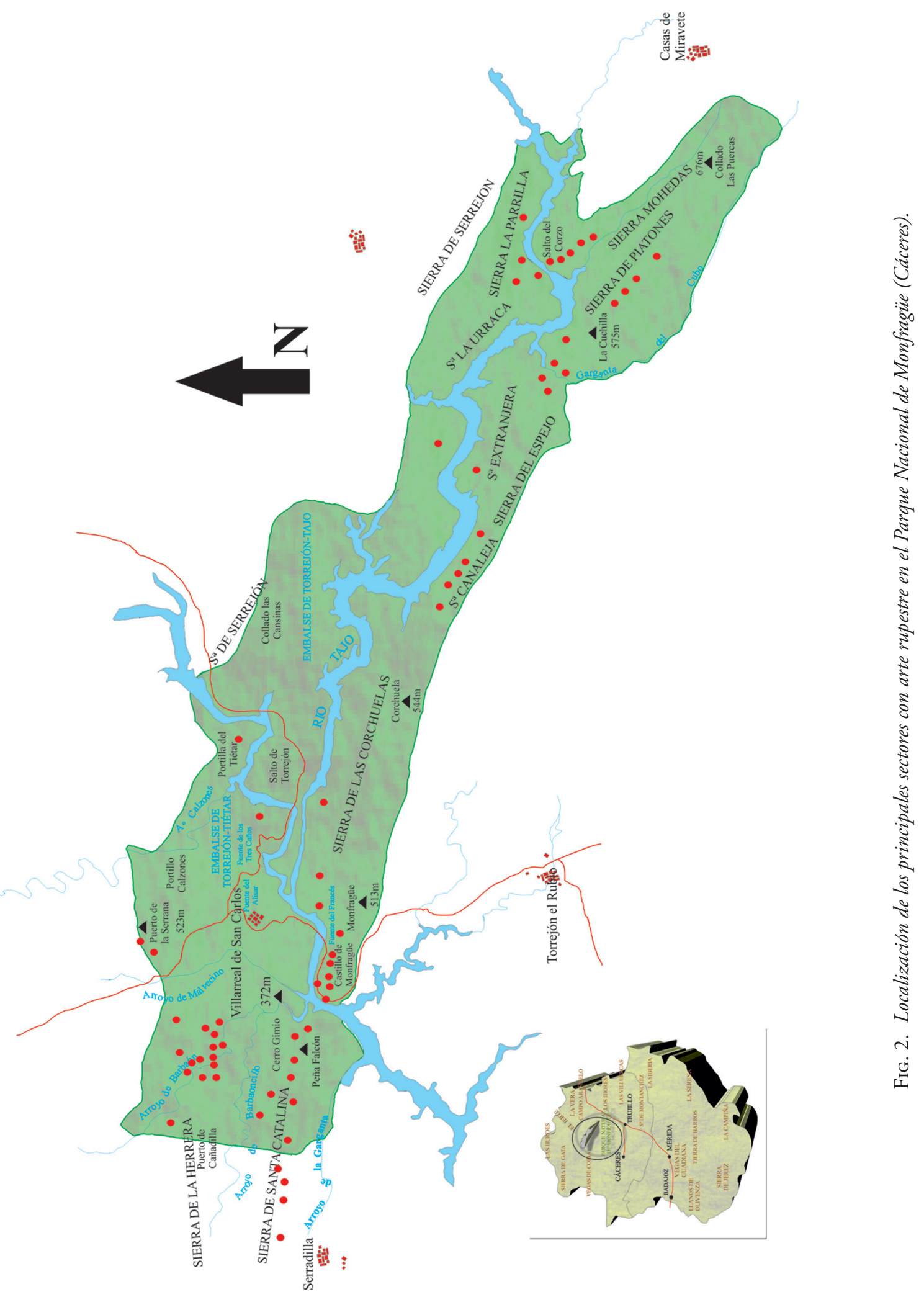


- Sector de la sierra de Piatones -término de Jaraicejo-, situado frente al Salto del Corzo, que reúne 4 estaciones.

- Sector de la Portilla del Arroyo del Cubo -término de Jaraicejo-, distribuido a ambos lados, E y $\mathrm{o}$, de la mencionada portilla, suma 5 estaciones.

- Sector del Salto del Corzo -término de Serrejón-, situado en el lado $\mathrm{N}$ del mismo, en él se localizan 2 estaciones.

- Sector de la sierra de Miravete-Mohedas -término de Casas de Miravete-, o zona comprendida entre la antigua carretera N-V -Madrid-Lisboa-, a la altura del actual túnel de Miravete, y el Salto del Corzo -lado s-. Esta zona cuenta con 7 abrigos pintados.

- Sector de la sierra de La Parrilla -término de Serrejón-: situado en el área oriental del Parque, y prospectado aún muy someramente. Hasta la fecha ha proporcionado tan sólo 1 abrigo decorado.

- Sector de la sierra de Navacalera -término de Serrejón-: área aún pendiente de una revisión en profundidad, en la que hasta la fecha se conoce una sola estación.

La conexión entre el arte rupestre de este espacio natural y los cursos de agua que, como apuntábamos con anterioridad, permeabilizan y permiten la transitabilidad a través del mismo, es un aspecto que debe tenerse muy en cuenta, como se ha puesto repetidamente de manifiesto en todos aquellos enfoques que, desde el punto de vista de la funcionalidad, vinculan arte rupestre y territorio (Martínez García, 1988; García Arranz, 1990; Bradley y Fábregas, 1999; Torregrosa, 2000-2001; Collado y García Arranz, 2001, 2005; Mateo, 2003; Bader, 2006; Fairén, 2006; Utrilla y Martínez Bea, 2009)². De hecho, en el ámbito geográfico de Monfragüe, más del $90 \%$ de las estaciones con arte rupestre se encuentra orientado visualmente hacia alguno de estos cauces, en un proceso de organización y control territorial en el que los enclaves decorados

2 Cf. también Cruz Berrocal, M. (2003): Paisaje y arte rupestre. Ensayo de contextualización arqueológica y geográfica de la pintura levantina. Tesis doctoral inédita presentada en 2003 en la Univ. Complutense de Madrid. tienden a concentrarse, además, en torno a lugares estratégicos para el tránsito, como las estrechas portillas que flanquean los cauces fluviales del parque -Salto del Gitano, Salto del Corzo, Portilla del Tiétar, etc.- o sus diversos puertos y collados; estas formaciones naturales brindan auténticos corredores de paso a través de las alineaciones serranas del parque a las vías tradicionales que, de norte a sur, vienen comunicando las planicies de la penillanura trujillano-cacereña con las tierras altas del $\mathrm{N}$ de la provincia de Cáceres.

Sin embargo, el hecho de que la mayor parte de los abrigos estudiados se encuentre en la vertiente de solana no parece responder a una posible estrategia de control mediante la mencionada apropiación simbólica del territorio, pues entendemos que tal preferencia es el resultado de un grado diferencial de conservación de las manifestaciones rupestres, derivada de las más difíciles condiciones de preservación de las superficies rocosas situadas en umbría. A los efectos, se ha comprobado que la excesiva humedad que opera sobre estos paneles provoca en muchas ocasiones el desarrollo de pátinas y oscurecimientos de la superficie, a lo que se suma una proliferación más intensa de colonias de líquenes y musgos, favorecida por las condiciones comentadas, que en no pocas ocasiones, como hemos tenido la posibilidad de comprobar, ha cubierto y ocultado una buena parte de las representaciones gráficas.

Desde criterios estrictamente morfológicos, los lugares que contienen manifestaciones rupestres en el Parque Nacional de Monfragüe han sido clasificados en cinco categorías diferentes (Collado, 2009):

a) Estaciones tipo I: grandes abrigos, con profundidad y/o amplitud que superan los $10 \mathrm{~m}, \mathrm{y}$ que suelen presentar igualmente un importante desarrollo en altura. Son fácilmente detectables en el paisaje, y su acceso no suele presentar excesivas complicaciones.

b) Estaciones tipo II: abrigos o covachas de cierta amplitud y una profundidad variable, aunque sin llegar a superar los $10 \mathrm{~m}$ desde el umbral de acceso, conformando ambientes que pueden servir fácilmente de refugio a una o varias personas.

c) Estaciones tipo III: paredes lisas - espejos de estrato- ligeramente inclinadas hacia la ladera y plenamente expuestas al aire libre. Tan solo el ligero desplome que muestran estas superficies, permite la 
protección de los motivos frente a las inclemencias atmosféricas.

d) Estaciones tipo IV: estaciones localizadas sobre grandes bloques de derrubio desprendidos de las cresterías cuarcíticas o en zonas de afloramientos graníticos que, al depositarse sobre otros bloques, conforman pequeños refugios protegidos de los agentes ambientales.

e) Estaciones tipo v: pequeñas oquedades o grietas de reducidas dimensiones, insuficientes en su mayoría para cobijar a un solo individuo completo, y siempre con un acceso estrecho que obliga a una posición forzada en su espacio interior para visualizar las pinturas.

Enmarcados en estos abrigos, independientemente de su tipología, se ha documentado un amplio conjunto

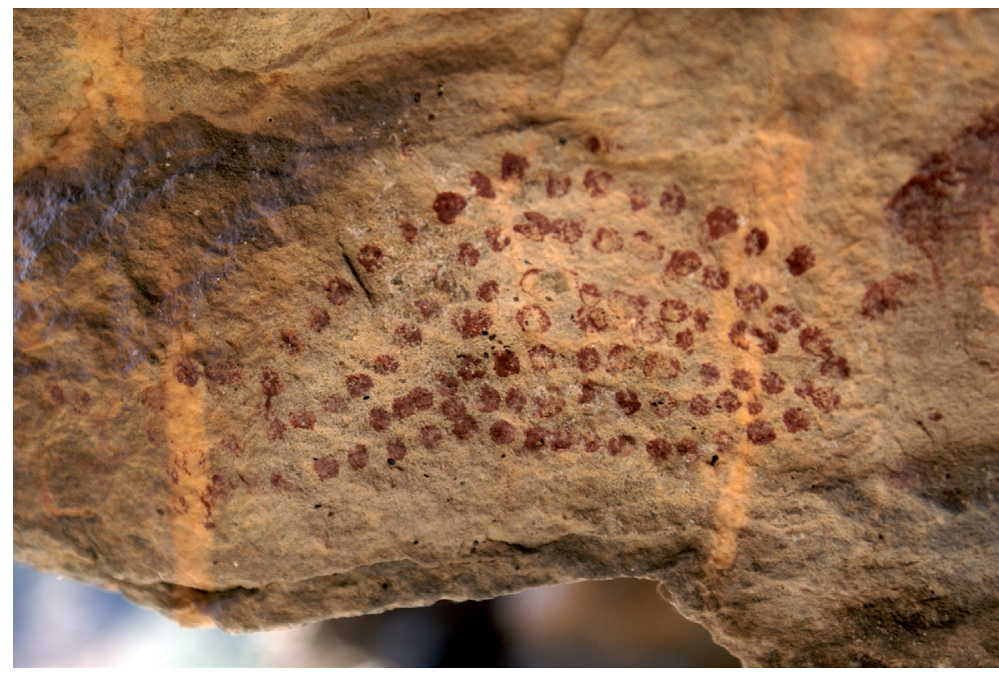

FIg. 3. Agrupación de puntos en el abrigo del Mirador conformando una figura similar a un pez. figurativo, generalmente bien conser-

vado, debido fundamentalmente a que la mayor parte de los yacimientos con arte rupestre se localizan dentro de áreas restringidas a la visita pública y vigilados constantemente por la guardería del parque, alejados de los itinerarios y áreas de acceso libre. Únicamente algunos lugares conocidos de antiguo, como la Cueva del Castillo, evidencian actos vandálicos como el piqueteado con una piedra sobre alguno de sus paneles más visibles.

La pintura es, con diferencia, la técnica más utilizada en las estaciones rupestres del Parque Nacional a la hora de realizar las representaciones. El grabado, en sus variantes incisa y piqueteada, también se halla presente, aunque minoritariamente, en el conjunto figurativo del Parque.

Centrándonos en la pintura debemos señalar que, dentro del carácter esencialmente lineal de los motivos propios del ciclo esquemático, el grosor de los trazos con que fueron ejecutados los pictogramas resulta muy variado, oscilando entre un máximo que puede alcanzar los $2 \mathrm{~cm}$ de ancho y las delgadas y precisas líneas 'filiformes' de escasamente $1 \mathrm{~mm}$, si bien el término medio habitual se sitúa en torno a $1 \mathrm{~cm}$ de anchura, lo que parece responder al empleo del dedo impregnado en pigmento como instrumento pictórico más recurrente. Resulta frecuente apreciar la utilización de diferentes tipos de trazo sobre un mismo motivo, empleándose el fino para incidir en determinados detalles, habitualmente de carácter etnográfico o de prestigio -tocados, objetos, adornos, etc.-, que complementan a la figura principal, por regla general dibujada en línea gruesa. Mucho menos frecuente, aunque no falta algún ejemplo, es la aplicación de tintas planas como relleno interior de parte de determinados motivos, especialmente los de tipo zoomorfo seminaturalista. Finalmente nos parece reseñable, por su singularidad en el conjunto de arte rupestre de Monfragüe, la aplicación del puntillado como sistema representacional a la hora de proporcionar 'corporeidad' o 'volumetría' a algunos grafemas. Esta técnica, consistente en elaborar ciertas figuras por medio de la acumulación premeditada de series o agrupaciones de puntos de tamaño similar, ha sido documentada claramente en el abrigo del Mirador -Arroyo Barbaón-, en el que, mediante pequeños puntiformes cuidadosamente elaborados y agrupados, se perfila una silueta que podría recordar a la de un pez (Fig. 3).

En lo relativo a los sistemas o instrumentos de aplicación de la pintura, el arte rupestre de Monfragüe no difiere de cualquier otro grupo esquemático peninsular. Ya hemos dicho que la aplicación del pigmento con el dedo sería lo más habitual y, de hecho, en el abrigo del Cajón -Sierra de Santa Catalina, Serradilla-, se ha podido documentar en el arranque de un trazo horizontal la huella dactilar del autor. No obstante, no se debe obviar que en la ejecución de los trazos de menor grosor se debieron 


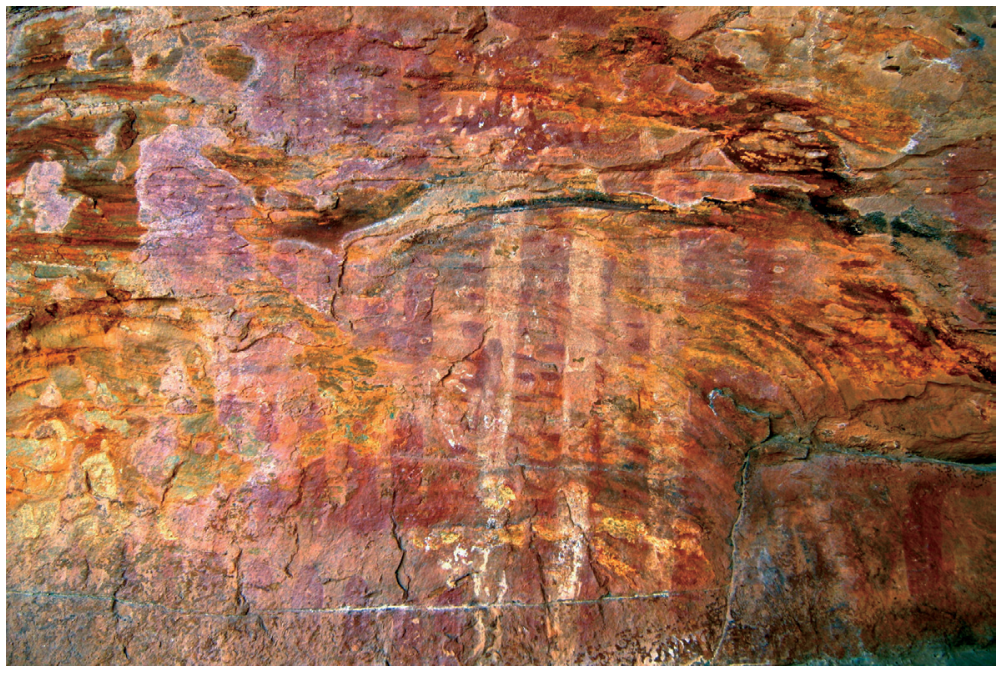

FIG. 4. Pigmentos rojos y blancos en el abrigo del Espolón conformando motivos bicromos.

utilizar elementos auxiliares como plumas, palitos de punta aguzada o incluso pinceles de fibra vegetal o pelo animal. Cabe mencionar en este apartado lo que parece ser una especie de "prueba de pintura" sobre la roca en el abrigo de Paqui -Sierra de Santa Catalina, Serradilla-, una mancha de contorno irregular en color rojo, en cuyo interior se han conservado, trazadas en diversas direcciones, evidentes improntas del paso de un pincel.

En relación con los pigmentos utilizados, cuestión sobre la que volveremos a incidir con mayor detalle en el apartado dedicado a las analíticas, el rojo es claramente predominante, aunque también se constata, de forma muy limitada, el uso del blanco y el negro. De forma general estos tonos se aplican de manera independiente en cada motivo individualizado, generando figuras monocromáticas. Sin embargo, en el abrigo del Espolón -Arroyo Barbaón, Serradilla - ha sido documentada una serie de combinaciones cromáticas que resulta extraordinariamente singular, no sólo en el conjunto del parque, sino en el panorama general de la pintura rupestre esquemática extremeña. Además de abundantes digitaciones de color blanco superpuestas a otras rojizas, se observa una serie de largos y gruesos trazos, también blancos, verticales y paralelos entre sí, festoneados en todo su recorrido mediante abundantes motivos rojos de trazo fino, rectos o curvados; estos últimos fueron realizados con el propósito de producir la sensación óptica de que el fino trazo en rojo se superpone e infrapone consecutivamente al trazo vertical en blanco, y viceversa (Fig. 4). En este mismo abrigo también hay que destacar por su bicromía una singular figura, a modo de doble ancoriforme, realizada en color rojo y ribeteada en todo su contorno por pequeńos trazos negros radiales, así como algunas figuras rojas igualmente contorneadas por pequeñas puntuaciones en pigmento blanco.

Desde criterios estilísticos el esquematismo, en sintonía con el ciclo rupestre prehistórico más representativo de Extremadura, es el modo de representación habitual en el complejo rupestre del Parque Nacional. En mucha menor proporción, se detectan algunas pictografías emparentadas con el ciclo preesquemático precedente (Collado y García Arranz, 2010), en el que prima formalmente una concesión hacia un mayor naturalismo figurativo, especialmente en las representaciones animales, siendo en este sentido significativos los motivos zoomorfos infrapuestos a los antropomorfos de la Cueva del Castillo. Volviendo al ciclo esquemático, los grafemas más sintéticos, sobre todo puntos, barras y digitaciones, se erigen como los motivos más habituales en la iconografía del Parque; a ellos se suman algunos pictogramas de carácter geométrico -cuadrangulares, circulares, soliformes, espirales, zigzags, tectiformes...- y, en porcentajes muy reducidos, diversas figuras humanas y animales.

\section{El abrigo del Friso del Terror y su contextualización arqueológica en el sector del Arroyo Barbaón}

El Arroyo Barbaón, ya lo hemos indicado anteriormente, es uno de los afluentes tributarios del Tajo por su margen derecha durante su recorrido por el territorio de Monfragüe. Este modesto curso de agua se localiza en la zona centro-occidental del parque, y desde su cabecera discurre sinuosamente de $\mathrm{N}$ a $\mathrm{S}$ atravesando en su etapa inicial las amplias superficies de la penillanura placentina, a través de 
frondosos campos adehesados de encinas y alcornoques con pastos abundantes -dehesas de Palazuelo, de Casa de Marcos, del Casar de Elvira, etc.-, hasta alcanzar la sierra del Casar de Elvira, una de las múltiples formaciones montuosas que flanquean el curso del río Tajo, y que constituyen una auténtica barrera natural que separa esta importante cuenca fluvial de las tierras llanas situadas hacia el N. A partir de este momento, el Barbaón se encaja profundamente entre potentes farallones de cuarcitas a lo largo de un trayecto de casi $3 \mathrm{~km}$ aguas abajo. Conforma de este modo un tramo singular desde un punto de vista orográfico, de notable atractivo paisajístico, donde ha sido descubierto uno de los conjuntos de arte rupestre más importantes y significativos de Monfragüe, constituido por 29 abrigos con pintura rupestre esquemática.

Tan especial orografía singulariza este espacio, al tiempo que se erige en factor determinante para la distribución de las rocas pintadas en esta zona. En este sentido, queremos llamar la atención sobre el hecho de que es el propio cauce del Barbaón el único ámbito que posibilita la comunicación N-S a través de un entorno agreste, complicado para el tránsito por su carácter accidentado y por su cerrada cobertura vegetal. El problema se acentúa por la difícil accesibilidad del profundo cauce del arroyo en el tramo descrito, un área clausurada al norte por la sierra del Casar de Elvira y, en su discurrir hacia el sur, por las grandes paredes rocosas que encajan y canalizan sus aguas (Fig. 5).

Es en este contexto físico donde se localiza el denominado Friso del Terror, que alberga las pinturas sobre las que se han aplicado los estudios analíticos que presentamos en el siguiente apartado. Se trata de una peculiar estación de unos $30 \mathrm{~m}$ de longitud que se articula como una sucesión longitudinal o 'en friso' de más de medio centenar de paneles con manifestaciones rupestres, apenas protegidos por viseras pétreas poco salientes o totalmente expuestos al aire libre. Estas superficies decoradas se encuentran precedidas por una estrecha repisa, colgada a más de $10 \mathrm{~m}$ de altura sobre el cauce del arroyo, en la zona media de un gran farallón rocoso prácticamente vertical, plataforma a la que actualmente resulta muy difícil acceder si no es con la ayuda de material de escalada (Figs. 6-7).

$\mathrm{Al}$ margen de la extremada dificultad que implica el acceso al abrigo, teniendo en cuenta que estas

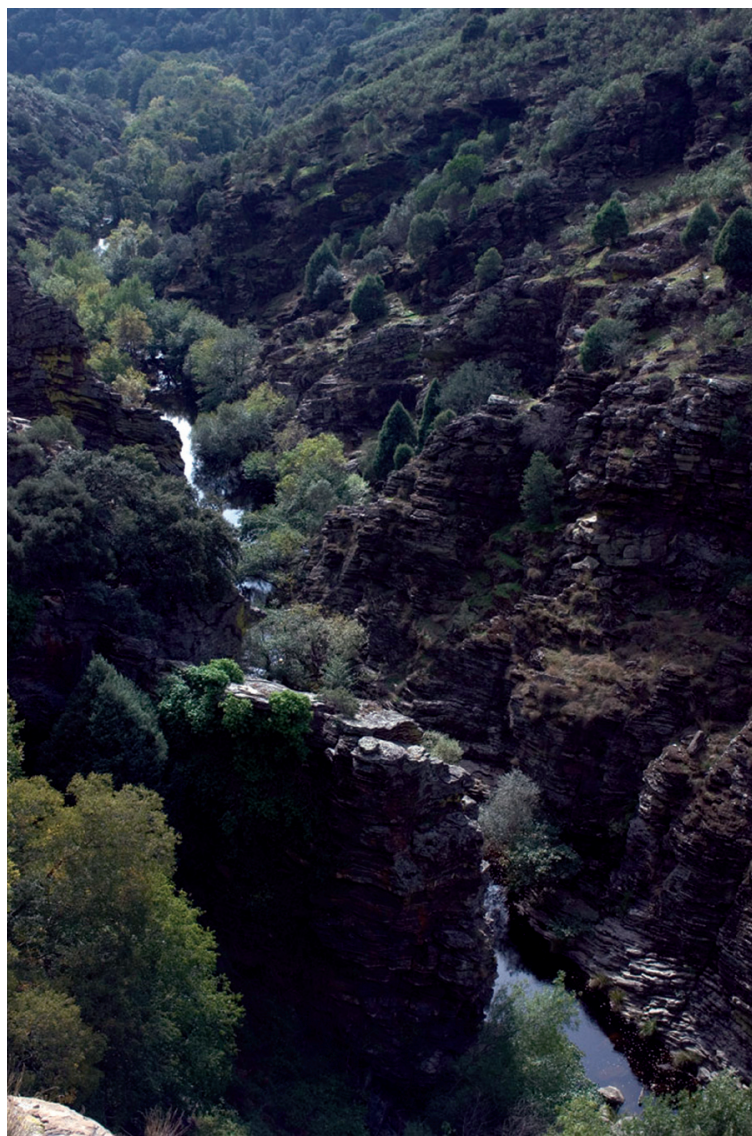

Fig. 5. Aspecto del cañón de la Portilla del Barbaón (Parque Nacional de Monfragüe).

condiciones deben haber variado poco o nada desde los tiempos prehistóricos, llama rápidamente la atención la singular iconografía que fue plasmada sobre sus superficies rocosas. En el Friso del Terror tan solo encontramos representadas series de barras verticales en paralelo en cada uno de sus 54 paneles. El número de figuras de cada serie es aparentemente aleatorio, existiendo tan sólo un panel en el que encontramos una barra aislada. No figura entre los propósitos del presente trabajo el planteamiento de hipótesis interpretativas, pues excedería sus objetivos iniciales, máxime cuando nos enfrentamos a grafemas tan sumarios y elementales como son las barras. Sin embargo, si tenemos en cuenta la privilegiada situación de "control" que este abrigo presenta sobre buena parte del estrecho cauce del Barbaón, no nos parece descabellado relacionar este contenido gráfico con sencillos sistemas de contabilidad 


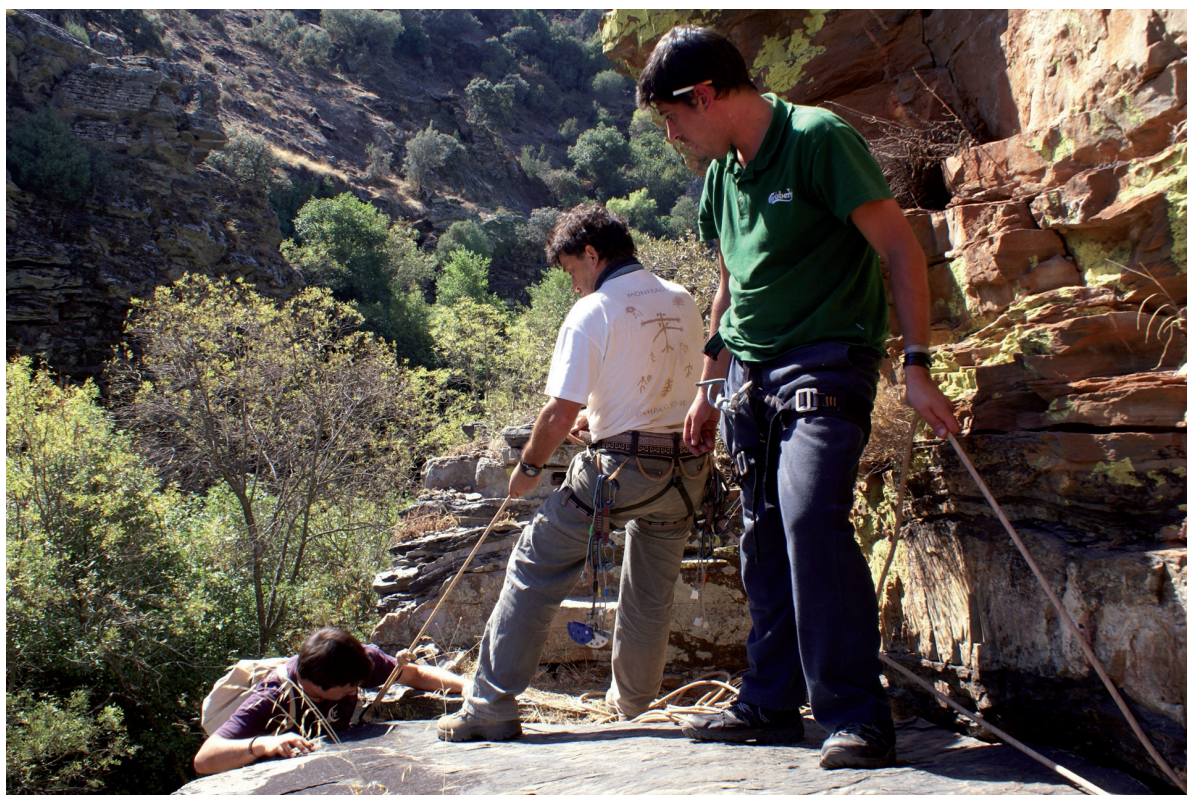

Fig.A 6. Accediendo al Friso del Terror (Arroyo Barbaón, Parque Nacional de Monfragüe). alinea a lo largo de la plataforma más próxima al cauce, aprovechando los elevados farallones verticales que enmarcan el discurrir de las aguas en esta zona.

De este modo, los puntos principales de entrada o salida al cauce están 'dominados' por estaciones pictóricas de considerables dimensiones, conformando cavidades claramente perceptibles en el paisaje a media y larga distancia y que pudieron funcionar como auténticos hitos de referencia - ¿tal vez con una finalidad informativa o de advertencia?- para aquellas personas que discurrían por el entorno

ejercidos sobre el itinerario que articula el propio cauce del arroyo desde este singular "punto de vigilancia", teniendo en cuenta además los particulares condicionantes físicos que supeditan el acceso al fondo del cauce desde las zonas altas circundantes y cómo los lugares con arte rupestre de este sector se vinculan con ellos (Collado et al., 2011).

Continuando la línea argumental anterior, el acceso al cauce del Barbaón únicamente resulta posible a través de las denominadas 'entraderas' -2 por la margen o, las entraderas de la Peña del Ciervo y del Espolón, y una más por el costado E, el arroyuelo de la Huerta del Diablo-, unos estrechos canales abiertos entre los elevados afloramientos rocosos, donde la ladera se prolonga con fuertes pendientes hasta el propio arroyo; estos son, como ya hemos referido, los únicos lugares por los que, no sin cierta dificultad, podemos acceder a pie hasta el mencionado cauce. A ambos lados de estos 'corredores' de acceso, y en posiciones de dominio visual sobre los mismos, han sido localizados los abrigos decorados que responden a los tipos i y II de la serie morfológica definida más arriba, y que presentan los programas iconográficos más amplios y complejos del conjunto del Arroyo Barbaón; el resto de las estaciones -como es el caso del Friso del Terror-se o pretendían descender en su desplazamiento hasta el mismo cauce del arroyo.

En estos abrigos pintados que flanquean o 'vigilan' las 'entraderas', se articula un complejo imaginario de representaciones pintadas sobre paneles de mediano tamaño y dispuestas con una vocación eminentemente pública, ya que, en la mayoría de las ocasiones, los motivos son claramente perceptibles desde las inmediaciones de la covacha rocosa sin necesidad de acceder a su interior. El arte rupestre de estos enclaves se caracteriza no sólo por el amplio número de motivos que registran, por encima del medio centenar en todos los casos, sino también por la variabilidad tipológica que se documenta en ellos, que en su mayor parte, salvo barras, digitaciones y antropomorfos, no vuelve a darse en los abrigos del tramo inferior más vinculados al cauce. Aquí tienen cabida, además de las habituales series de trazos y puntiformes, los motivos ondulados, ramiformes, soliformes, ídolos oculados, tectiformes, círculos y antropomorfos -estos últimos, por regla general, con los brazos y las piernas en arco-, además de motivos indeterminados que escapan a las tipologías clásicas preestablecidas. Tan solo, de acuerdo con la tónica general del conjunto gráfico del Barbaón, se 
encuentran ausentes las representaciones claras de animales.

A esta variabilidad tipológico-temática se incorpora, en todos los casos, una notable diversidad técnica, en la que sigue primando el trazo grueso frente a los motivos confeccionados con líneas de grosor más reducido, y en las que se recurre al uso de diferentes tipos de pigmentos, blancos, negros y rojos, siendo estos últimos los claramente dominantes; también se constata, como recurso bastante excepcional en

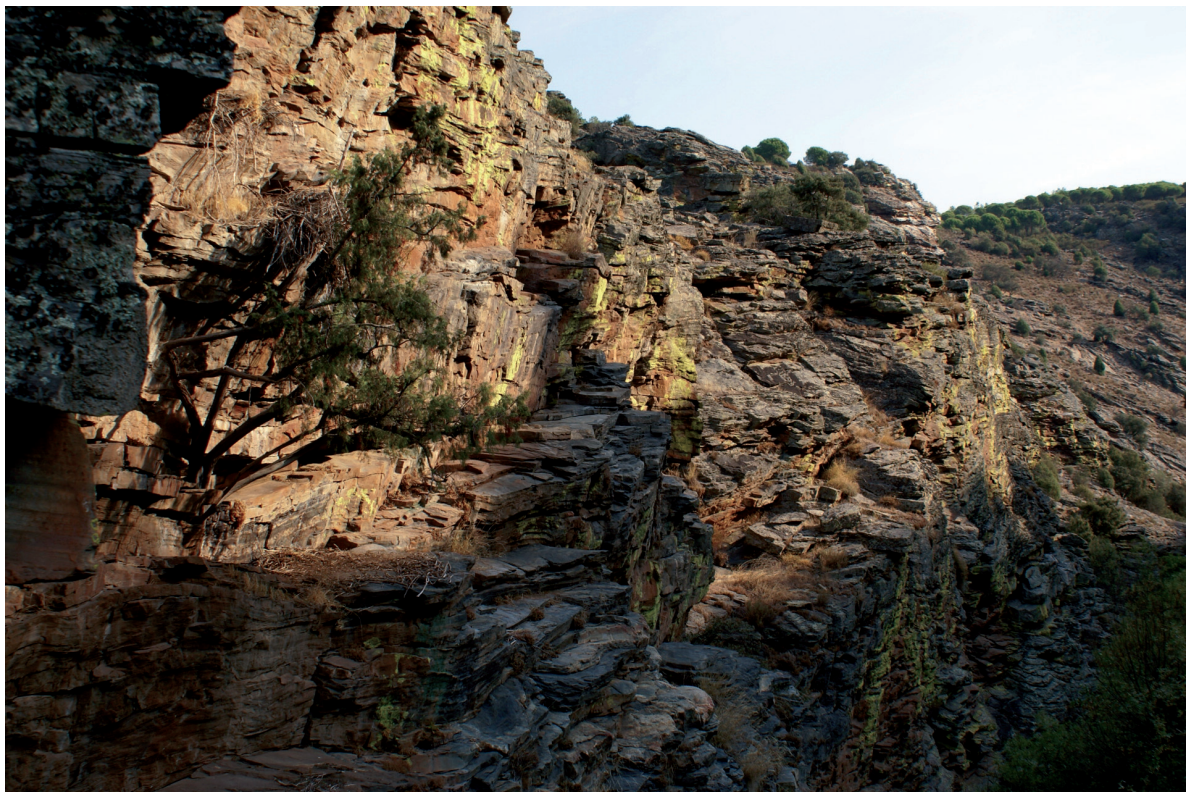

FIG. 7. Vista general de la cornisa rocosa del Friso del Terror. el ciclo esquemático peninsular y exclusivo con respecto a todo el ámbito del Parque Nacional, la bicromía figurativa, con la aplicación de dos pigmentos de color diferente a la confección de una misma figura (Fig. 4).

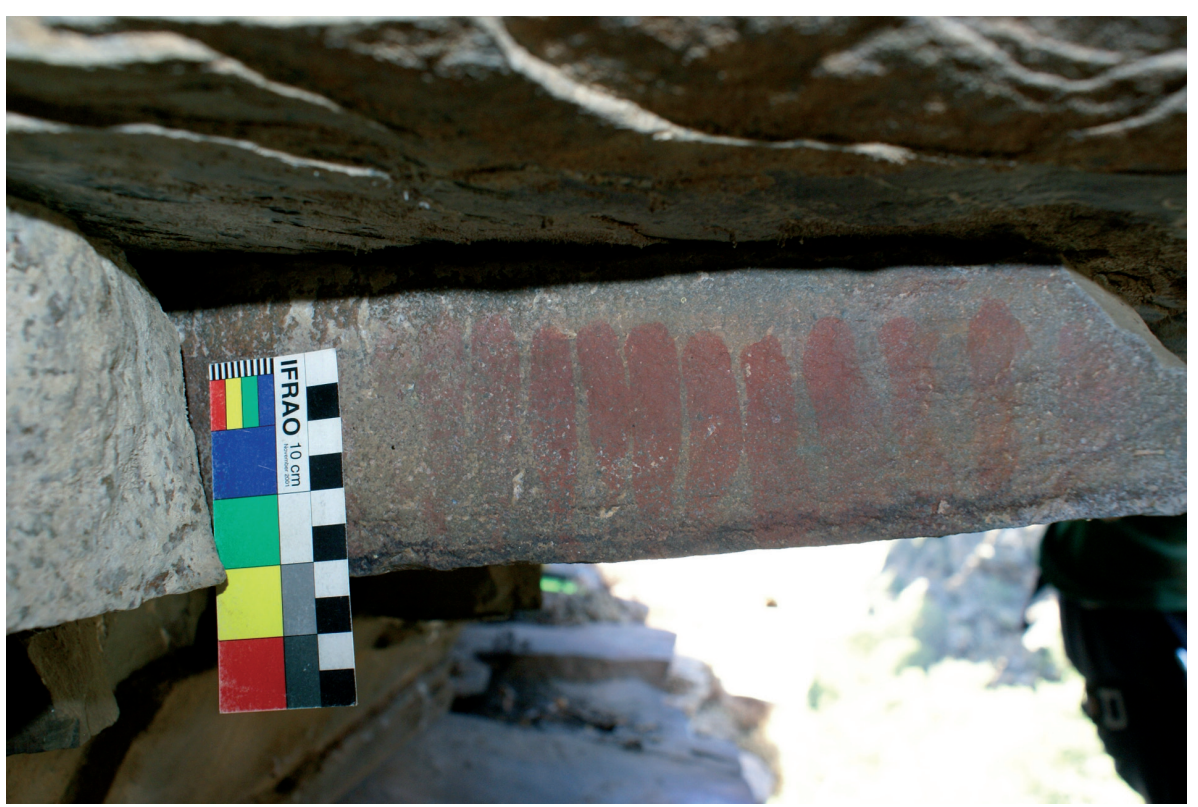

Fig. 8. Pictografias-series de barras- en el Friso del Terror.
La dinámica aquí expuesta cambia en los abrigos vinculados directamente al cauce del arroyo, localizados en el interior del estrecho cañón. En primer lugar, por el hecho de que su rango de visibilidad, al contrario de lo que sucede con los abrigos antes descritos, queda reducido al del propio cauce, siendo sus pinturas perceptibles únicamente desde la proximidad. Sin embargo, y con independencia de que se trate de los abrigos enmarcados en los tipos II o iII de la serie antes definida, que son los mayoritarios en este ámbito, se reitera el carácter público de los mismos, con sus paneles decorados expuestos claramente hacia el exterior de la cavidad, en una situación y a una altura fácilmente perceptibles para el espectador situado ante ellos. En 


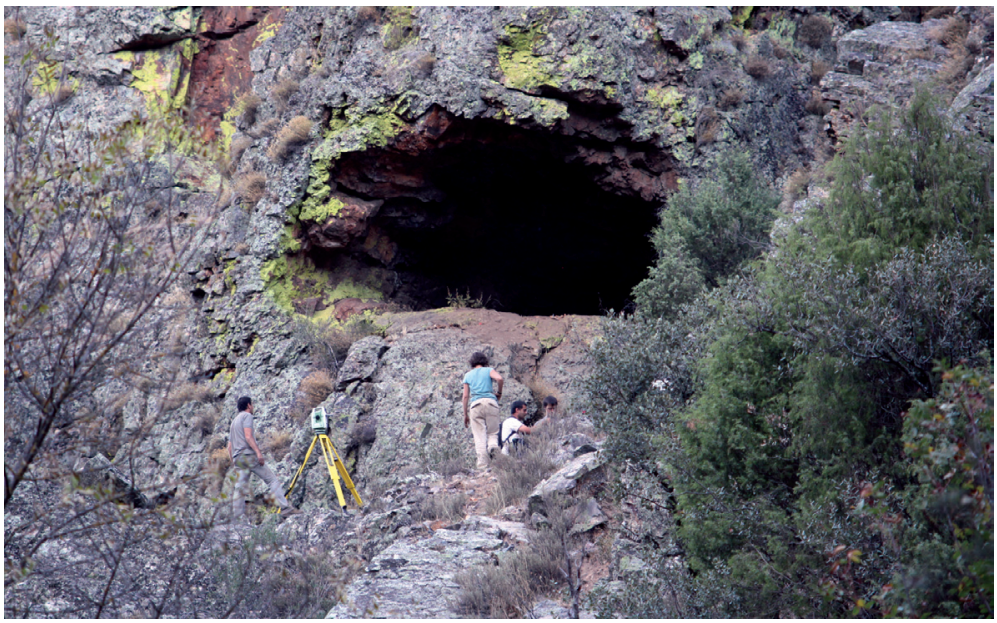

Fig. 9. Trabajos de topografía realizados por S. Pérez Romero previos al comienzo de la excavación en la Cueva del Sapo (Arroyo Barbaón, Parque Nacional de Monfragüe).
La excavación de este abrigo se efectuó durante la campaña de octubre de 2011, una vez obtenidos todos los permisos administrativos necesarios, y tras una minuciosa planificación que permitió superar la dificultad añadida de plantear una excavación en un enclave de acceso muy complicado (Fig. 9).

El interior de la Cueva del Sapo presenta una superficie aproximada de unos $70 \mathrm{~m}^{2}$, ocupando el afloramiento rocoso unas dos terceras partes de la misma. El resto, una pequeña franja dispuesta junto a la pared oriental, que conforma un corredor de aproximadamente $1,5 \mathrm{~m}$ de ancho, alberga un pequeño paquete de sedimento en cuya superficie, como consecuencia de remociones causadas por animales, fueron localizados los primeros fragmentos de cerámica.

estos conjuntos se disponen, de una manera casi monográfica, como sucede en el Friso del Terror, numerosas y prolongadas alineaciones de barras o puntiformes, en cuya confección se emplea exclusivamente el trazo grueso de color rojo (Fig. 8), y a las que se incorpora de manera muy ocasional un reducido número de antropomorfos, algún zigzag, un par de zoomorfos de pequeño tamaño y un ídolo oculado.

Tan solo escapa a esta tónica común la Cueva del Sapo, el único abrigo del tipo I que se sitúa en el interior de la garganta, justamente frente a la desembocadura de la 'entradera' de la Huerta del Diablo, y en el que tan sólo han sido localizados en su interior, y en zonas perceptibles no sin cierta dificultad, cuatro pequeños paneles decorados. En ellos se da cabida a un reducido número de grafemas, que incluye la única figura zoomorfa con ciertas concesiones hacia un estilo más naturalista documentada en todo el conjunto esquemático del Arroyo Barbaón. Además de estas características que la particularizan, resulta igualmente reseñable el hecho de que, en niveles superficiales del área interior de esta covacha rocosa, se recogieron varios fragmentos de cerámica a mano, lo que permitió constatar, mediante un pequeño sondeo estratigráfico, la única evidencia, hasta la fecha, de ocupación prehistórica vinculada a este entorno.
Ha sido en esta zona, a medio camino entre la entrada y el área más interior del abrigo, donde se planteó una cuadrícula de $1 \times 1 \mathrm{~m}$, orientada al $\mathrm{N}$ en uno de sus ejes, y previamente topografiada (Fig. 10).

La excavación se realizó por estratos naturales -unidades estratigráficas-, con posicionado de los elementos arqueológicos in situ, y recogida sistemática de muestras para los correspondientes análisis polínicos y antracológicos ${ }^{3}$. Todo el sedimento extraído fue tamizado con recogida en seco de los materiales, que fueron recopilados de manera sistemática y almacenados en bolsas individualizadas en función del tipo de objeto -cerámica, industria lítica o muestra vegetal-. Con posterioridad, el material recogido fue lavado e inventariado en laboratorio.

El sondeo puso de manifiesto cuatro unidades estratigráficas diferentes, cotejadas por el análisis sedimentológico ${ }^{4}$, que agrupan una potencia sedimentaria que alcanza los $30 \mathrm{~cm}$ en la zona de máximo espesor (Figs. 11-12).

${ }^{3}$ Los análisis palinológicos han sido realizados por C. Ferreira, del Grupo Quaternário e Pré-História, y los antracológicos fueron elaborados por D. Duque, del Área de Prehistoria de la Universidad de Extremadura.

${ }^{4}$ Los responsables de los análisis sedimentológicos han sido J. M. Fernández y E. Blasco, de la Univ. Politécnica de Madrid. 


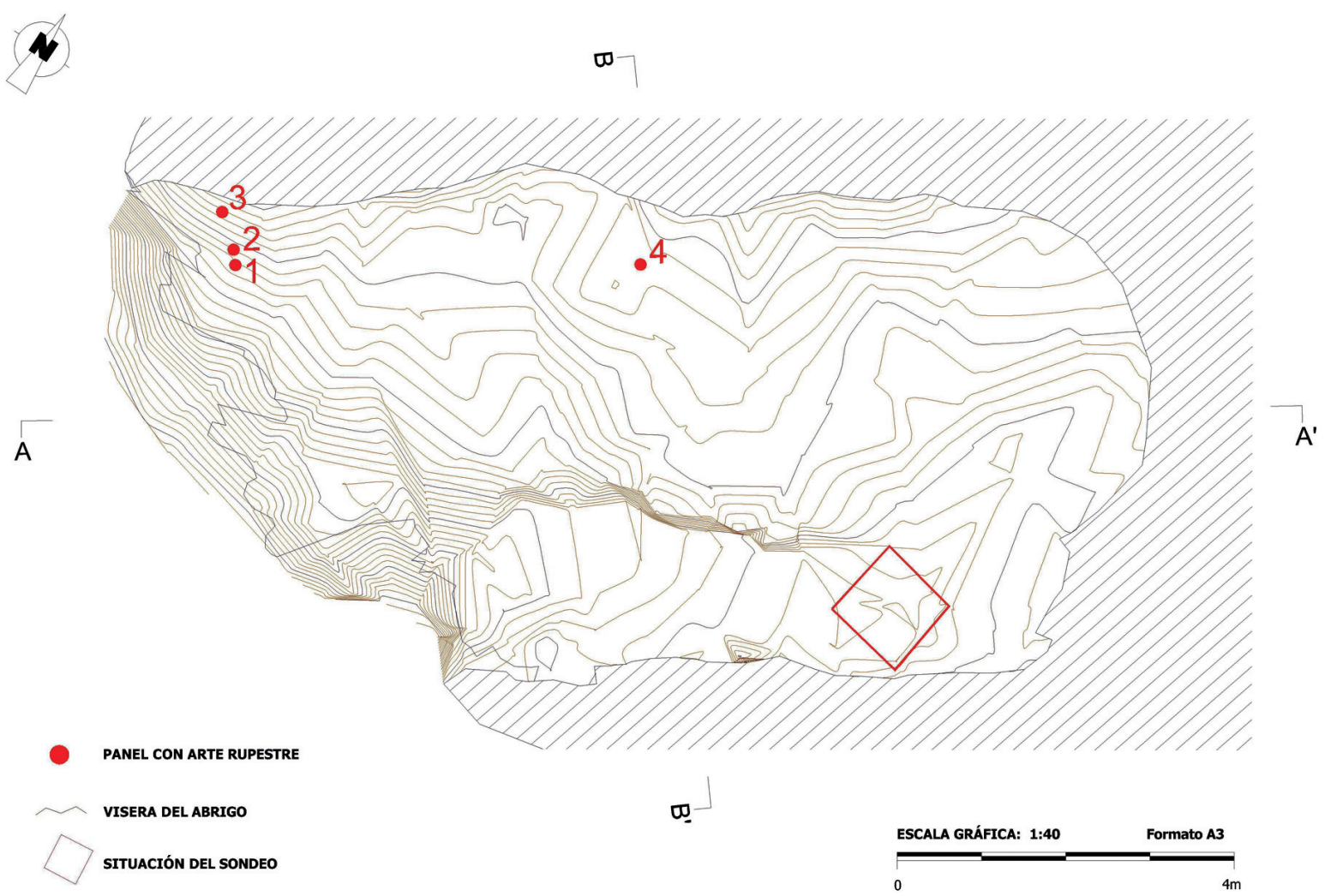

Fig. 10. Planta de la Cueva del Sapo con situación del sondeo y localización de los paneles pintados (dibujo de Samuel Pérez Romero).

- UE 1: se trata de la capa superficial de unos 7 $\mathrm{cm}$ de espesor medio, cuya textura es un sedimento suelto y arenoso de color marrón oscuro que incluye un porcentaje muy significativo de materia orgánica, principalmente carbón, cuyo origen hay que buscarlo en los restos de una hoguera -UE0- que los análisis paleobiológicos, a partir de los taxones identificados y su proporcionalidad -mayoritariamente enebro y en mucha menor proporción fresno-, relacionan con una "hoguera puntual y de corta duración".
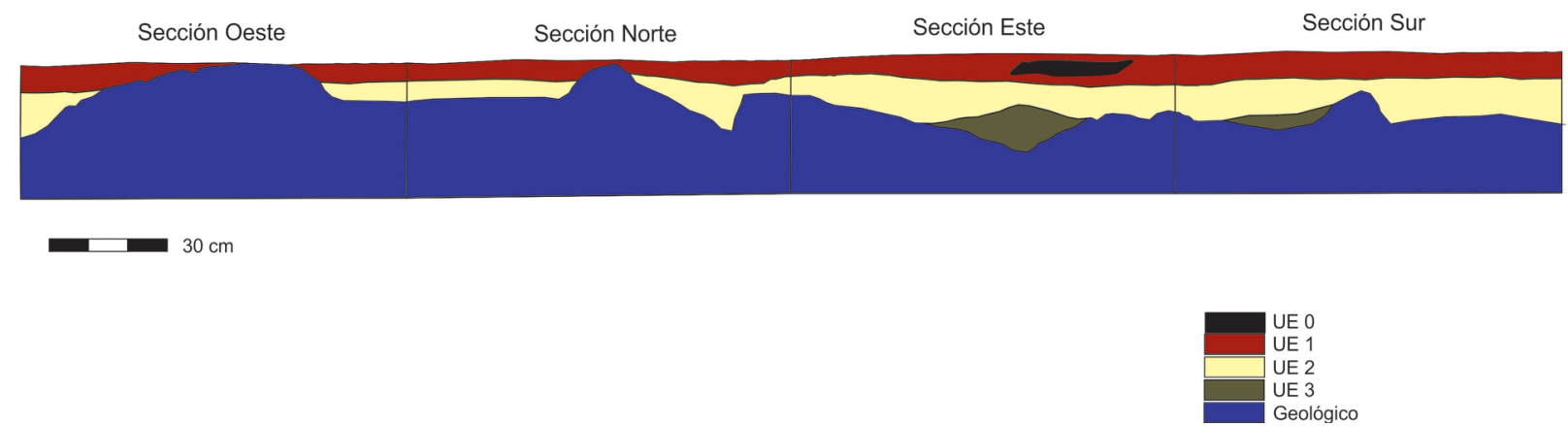

FIG. 11. Esquema de las secciones estratigráficas de la Cueva del Sapo en cada uno de los lados del sondeo. 


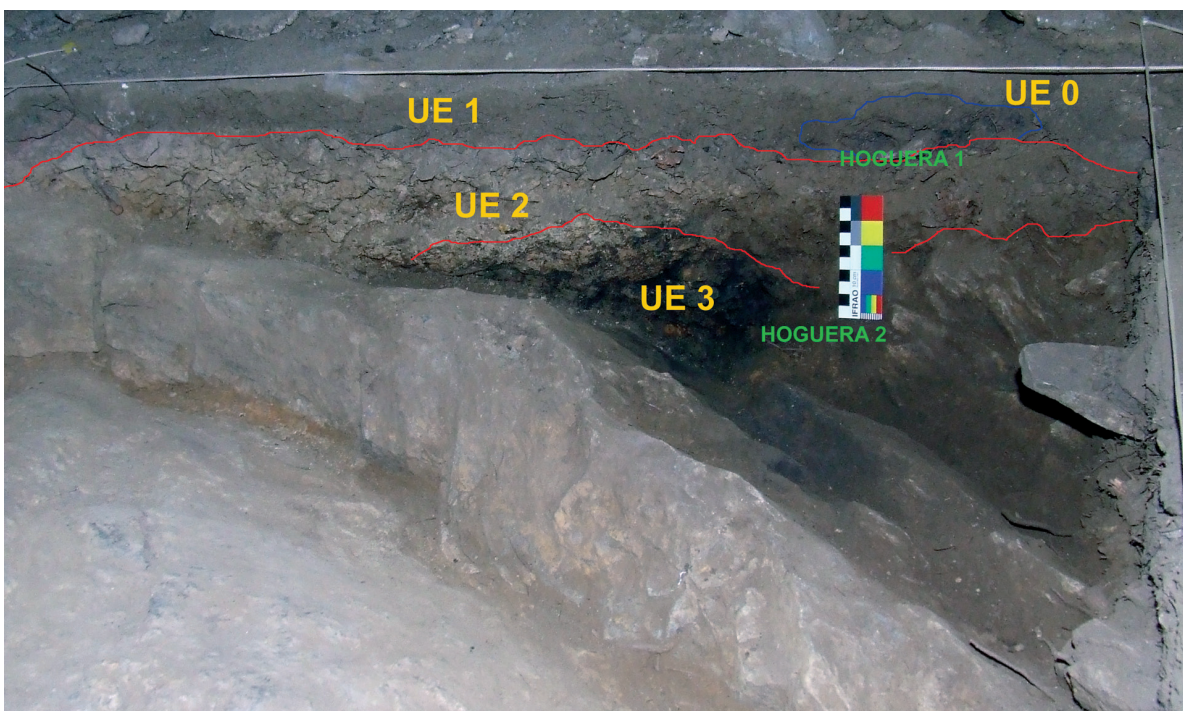

FIG. 12. Sección este de la excavación de la Cueva del Sapo con UE indicadas.

reductores $\mathrm{o}$ irregulares (oxidante-reductor) y en menor proporción en oxidantes (Fig. 13), habiéndose empleando para su confección únicamente desgrasantes de tamaño grueso $(>2 \mathrm{~mm})$ (el $55,5 \%)$ y medio $(1 / 2$ $\mathrm{mm})(44,5 \%)$.

Consecuencia de este tipo de cocción es que las pastas muestran mayoritariamente colores oscuros (8 fragmentos) y castaños -8 fragmentos-, siendo minoritarias las de tonos anaranjados -2 fragmentos-.

Ninguna de ellas pre-

Se trata de un estrato intensamente alterado por la acción de los animales, goteos superficiales y raíces, en el que se ha localizado la mayor parte del material recogido en el sondeo. De esta unidad procede la totalidad de los fragmentos de cerámica -18- y 5 elementos líticos.

Respecto a la cerámica, hemos de señalar que el $100 \%$ está realizada a mano; presenta un aspecto tosco, cocida en su mayor parte en ambientes

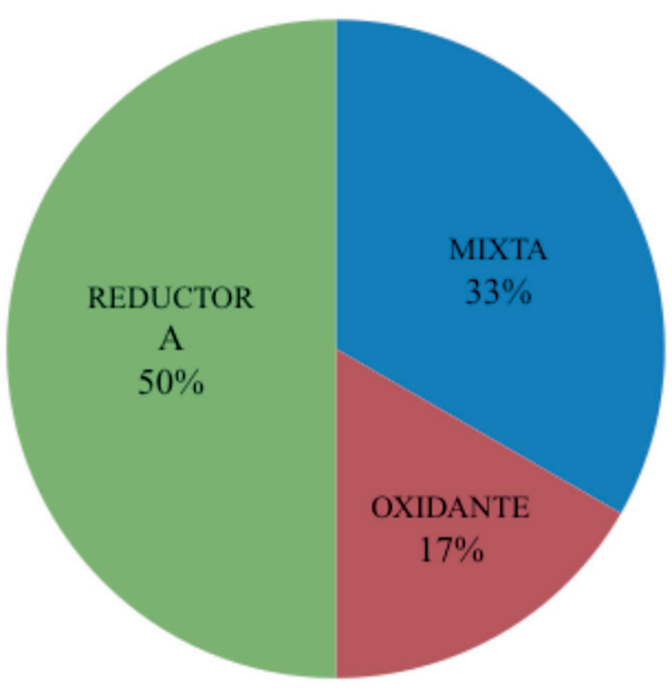

Fig. 13. Clasificación porcentual de los fragmentos cerámicos recuperados en la Cueva del Sapo. senta decoración, rematándose sus superficies con tratamientos alisados o, en no pocas ocasiones, dejándolas sin tratar. El origen de los fragmentos es diverso, ya que tan solo tres de ellos pueden considerarse, por sus características, procedentes de la misma pieza.

En la muestra recuperada se identifican recipientes toscos de paredes cuyo grosor oscila entre los 6 y 11,6 mm, encontrándose la media más reiterada en torno a los $8,5 \mathrm{~mm}$. Se trata de recipientes de mediano tamaño, de fondos ligeramente convexos y paredes rectas o ligeramente curvadas al interior. El único borde recuperado (.$^{\circ}$ inv. 7 ), que permite una reconstrucción bastante aproximada de la vasija, pertenece a un recipiente acastañado, posiblemente de fondo curvo, con paredes rectas que remataban en un labio aplanado de sección cuadrangular (Fig. 14).

El conjunto de objetos líticos recogido en esta unidad superficial (Fig. 15) corresponde a cinco pequeños fragmentos de sílex que han sido identificados como debrís (1) y restos de talla (4), aunque parece posible que uno de ellos corresponda al extremo distal fraccionado de una lámina de sección triangular (n. ${ }^{\circ}$ inv. 2). Son piezas de diferente color y textura, de tamaño reducido, que muestran en la mayor parte de los casos pequeñas huellas de extracción por presión, y que denotan el intenso aprovechamiento que de este tipo de material, bastante escaso en el entorno, hicieron los habitantes prehistóricos de la Cueva del Sapo. 
- UE 2: infrapuesta a UE1, y asentada directamente en su zona E y o sobre el afloramiento rocoso, y en el centro tapando la hoguera que ha sido identificada como UE3. El sedimento, con una potencia máxima de $10 \mathrm{~cm}$, presenta un color marrón, de textura arenosa y suelta con una matriz más pedregosa que la unidad anterior aunque con mucha menos materia orgánica.

Aparece menos afectado por la acción de la fauna y las raíces, que no obstante lo cortan en su lado $\mathrm{N}$ principalmente.

La cultura material recuperada en esta unidad se reduce exclusivamente a industria lítica, toda ella procedente de la zona de contacto con el techo de la UE 3, por lo que es factible una percolación desde la unidad precedente. Está conformada por tres piezas, un pequeño fragmento cúbico de cristal de roca y dos pequeñas lascas de sílex de diferente textura y color, con huellas de extracción por presión que pueden considerarse posiblemente como restos de talla, aunque de una de ellas no es descartable su identificación con un microlito geométrico tipo triangular (n. ${ }^{\circ}$ inv. 7 ).

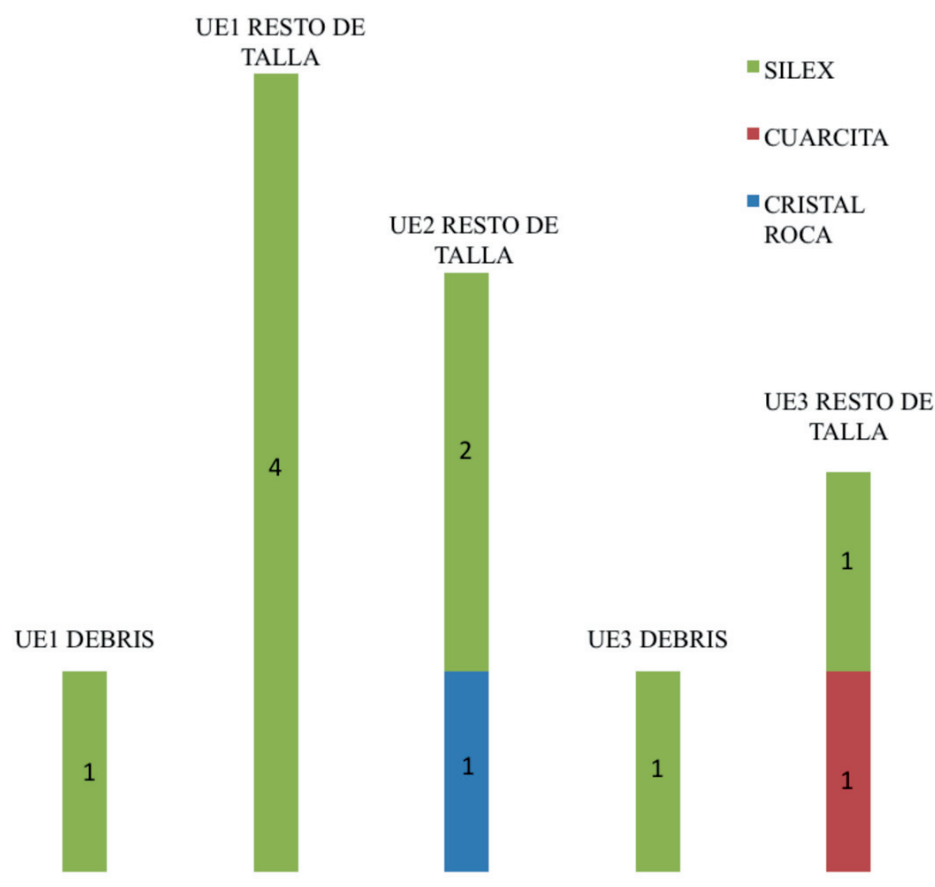

FIG. 15. Industria litica recuperada en las diferentes UUEE de la Cueva del Sapo.

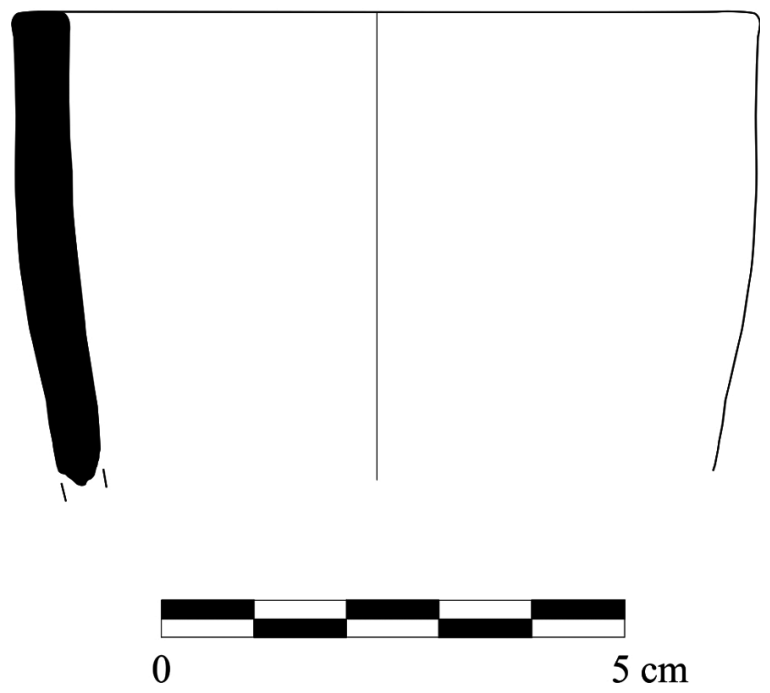

FIG. 14. Restitución de recipiente a partir de un fragmento de borde recuperado en la Cueva del Sapo (n. ${ }^{\circ}$ inv. 7). SAPO 2011 SUP7 Ø 8cm.

- UE 3: asentada directamente sobre la roca base e infrapuesta a UE 2. Ha sido identificada como los restos de un pequeño hogar que ocupa básicamente la esquina SE del sondeo (Fig. 16). Ha sido parcialmente excavada, quedando la mitad integrada en la sección E para futuros estudios. De ella se ha obtenido un amplio repertorio de muestras arqueobotánicas, que deben relacionarse con una mayor duración de la estructura de combustión. Los taxones presentes, que fueron usados como combustible, debieron ser recolectados en el entorno más inmediato entre especies habituales de estos roquedos, aunque la presencia relativa de especies como la encina-coscoja (Quercus ilex-coccifera), el acebuche (Olea europaea), el lentisco (Pistacia lentiscus), la jara (Cistaceae sp.), las leguminosas (Leguminosae sp.) y el madroño (Arbutus unedo) nos muestran la recolección en otros nichos de vegetación adaptados a laderas de solana y umbría, así como un posible grado de transformación de la vegetación circundante en formaciones más abiertas, quizás relacionadas con la actividad antrópica (pastoreo) en la zona circundante.

Esta unidad ha proporcionado únicamente tres objetos líticos, todos ellos de 


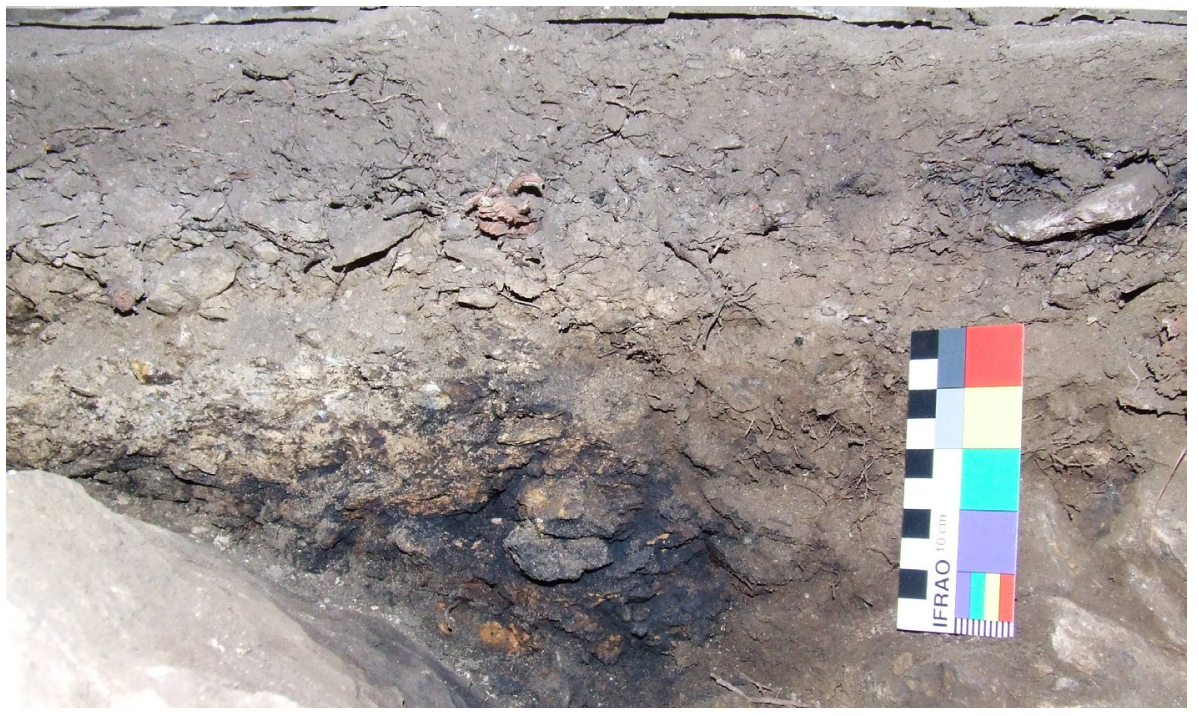

Fig. 16. Sección del hogar uE 3 de la Cueva del Sapo.

porádicos ocupantes que se marcharon.

A día de hoy, nos resulta imposible saber si los grupos que ocuparon el interior de la Cueva del Sapo guardan algún tipo de vinculación con la realización de las pinturas rupestres que se distribuyen por todo el entorno de Arroyo Barbaón, o incluso con las que decoran el propio abrigo. En cualquier caso, las características de los materiales y el tipo de ocupación nos remiten a un horizonte a caballo entre el Neolítico y los primeros momen-

pequeño tamaño, de los cuales dos son de sílex y uno de cuarcita. De nuevo nos encontramos con restos de talla, una actividad que debió desarrollarse en este abrigo en el entorno de las estructuras de combustión, debiendo destacar que uno de los fragmentos, el de cuarcita, podría corresponder con el extremo distal de una lámina de sección triangular (n. ${ }^{\circ}$ inv. 9).

La excavación realizada en la Cueva del Sapo evidencia la frecuentación de este abrigo en época prehistórica, pero no como un asentamiento permanente y estable, sino como un refugio ocasional usado por las personas que se movieron por este entorno, bien durante desplazamientos estacionales que aprovechaban el curso del Barbaón como una ruta para atravesar las sierras, o como un lugar adecuado para refugiarse durante las estancias cortas en el marco de partidas de caza o vigilancia de rebaños.

La propia idiosincrasia de este tipo de ocupaciones explica la pobreza de materiales localizados en la excavación, fundamentalmente restos de talla, una actividad que sería realizada durante los descansos, alrededor del fuego, en torno al cual caían los pequeños fragmentos desprendidos de los núcleos o del reavivado de piezas ya fabricadas.

La cerámica, escasa, hay que relacionarla con pequeños contenedores usados para cocinar o acopiar agua en el abrigo, y que posiblemente se rompieron o fueron abandonados en el refugio cuando sus es- tos de la Edad del Cobre, en el cual las manifestaciones rupestres del Arroyo Barbaón encuentran un buen acomodo, en el marco de un proceso de apropiación simbólica del paisaje que venimos describiendo, a través de la disposición de los abrigos y los dispositivos gráficos, en relación a la ruta de comunicación que constituye el cauce fluvial. Muy posiblemente la imposición de tan amplio y denso aparato simbólico sobre un accidente orográfico singular tendría como objeto principal humanizarlo, y dotarlo de unas señales que no fueron más que el reflejo de su control y uso por parte de las comunidades prehistóricas entre el v y el IV milenio antes de nuestra era.

\section{Caracterización de los pigmentos utilizados en los motivos esquemáticos del abrigo del Friso del Terror}

Dentro de las posibilidades que la Arqueometría nos ofrece en cuanto a sus aplicaciones al estudio del arte rupestre -entre las que pueden englobarse distintas técnicas de análisis (Raman, XRF, FTIR, etc.), con distintas aproximaciones metodológicas (destructivas vs. no destructivas, in situ vs. laboratorio)-, es sin duda la caracterización de los pigmentos con los que se elaboraron las pinturas la 
que viene suscitando mayor interés dentro de la investigación especializada. El objetivo fundamental de esta disciplina es, en síntesis, recrear el proceso de adquisición y preparación de los pigmentos, así como reconocer los procesos del deterioro biológico, todo ello en estrecha conexión con los problemas de conservación del arte rupestre. La composición mineral, los materiales de procedencia natural, los aglutinantes orgánicos y los procesos de manufactura de los colorantes constituyen el punto de interés prioritario de la caracterización de pigmentos. Entre todos estos componentes suelen ser los aglutinantes, preferentemente orgánicos, los más difíciles de detectar a causa de su gran diversidad y del comprensible proceso de degradación experimentado a lo largo de miles de años, por lo que, en caso de preservarse, se encuentran a niveles de simples trazas, lo que dificulta de manera considerable su apreciación (Cristini et al., 2010; Hernanz et al., 2007; Prisloo et al., 2008; Smith y Clark, 2004).

El hecho de contar con una placa de cuarcita localizada en el mencionado abrigo del Friso del Terror, desprendida de forma natural de su panel original y que conservaba restos de pinturas rupestres -representación parcial de dos barras (Fig. 17)-, nos ha proporcionado la posibilidad de aplicar con comodidad diferentes técnicas de análisis arqueométrico, que se llevaron a cabo en colaboración con el Dpto. de Física y Ciencias de la Tierra de la Univ. de Ferrara, en Italia, con el fin de obtener la caracterización de los paneles de arte rupestre de la mencionada estación -pigmentos, óxidos naturales, concreciones y sustratos-, mediante análisis en los que metodológicamente se ha utilizado la espectroscopia Raman, la microfluorescencia-X y la microestratigrafía.

En el panel de donde procede el fragmento decorado desprendido que ha sido analizado, las pictografías fueron realizadas con ocre rojo, como igualmente se constata en el resto del aparato gráfico documentado en el Friso del Terror.

Aunque constituye el término común para designar la trituración del pigmento mineral para su uso en la creación artística desde los tiempos prehistóricos, el vocablo 'ocre' -literalmente 'amarillo' en griego- hace referencia, al mismo tiempo, a un

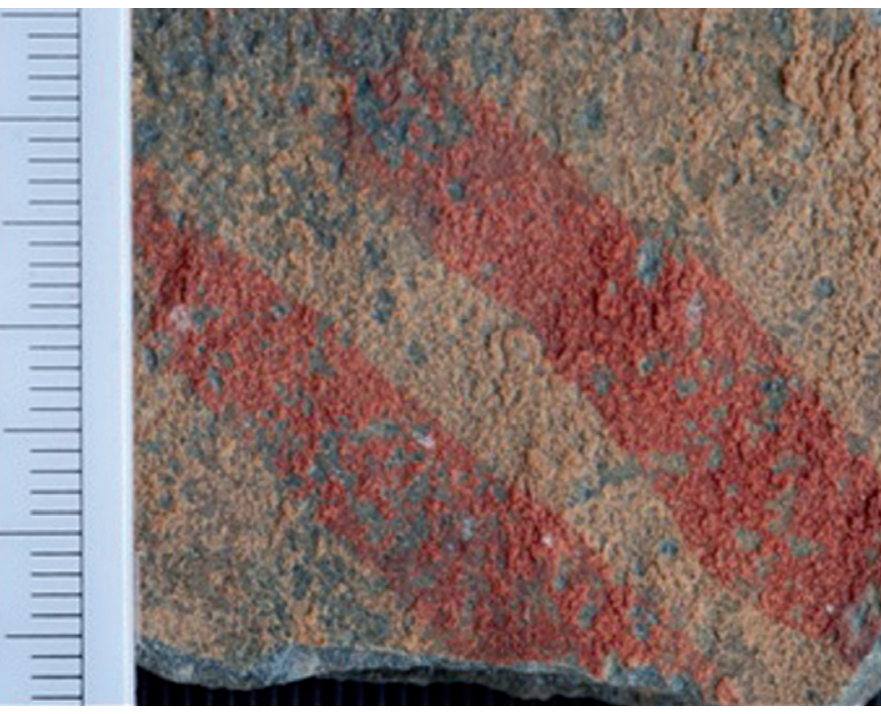

FIG. 17. Muestra recogida en el panel con arte rupestre del Friso del Terror.

compuesto de carácter genérico -mineral terroso consistente en hidra u óxido de hierro, que frecuentemente se presenta mezclado con arcilla, adquiriendo una tonalidad roja, amarilla o anaranjada en función de la proporción de las distintas fases minerales de óxidos de hierro que llegue a contener-. El ocre de color más amarillo es rico básicamente en óxido de hierro hidratado; de entre las diferentes fases minerales de óxido de hierro hidratadas, la goethita suele ser la más abundante por ser la más estable desde un punto de vista termodinámico. Si presenta color rojizo, la fase mineral más abundante sería el hematite, el óxido de hierro deshidratado. De hecho, la composición del ocre resulta variable incluso si la combinación esencial está formada por arcilla y óxido, existiendo, en función de su proporción, la posibilidad de formar sustancias diferentes (Hradil et al., 2003). Por otra parte, dada la presencia de abundantes contextos geológicos ricos en depósitos de materiales metalíferos en las proximidades de la estación rupestre analizada en el Arroyo Barbaón, la procedencia local de los pigmentos debería ser considerada como la más probable.

El estudio realizado está basado en el análisis de diversos elementos implicados en la elaboración, ejecución y conservación del arte rupestre. De este modo fueron recogidas para su caracterización muestras de diferente tipo: del pigmento con el que 

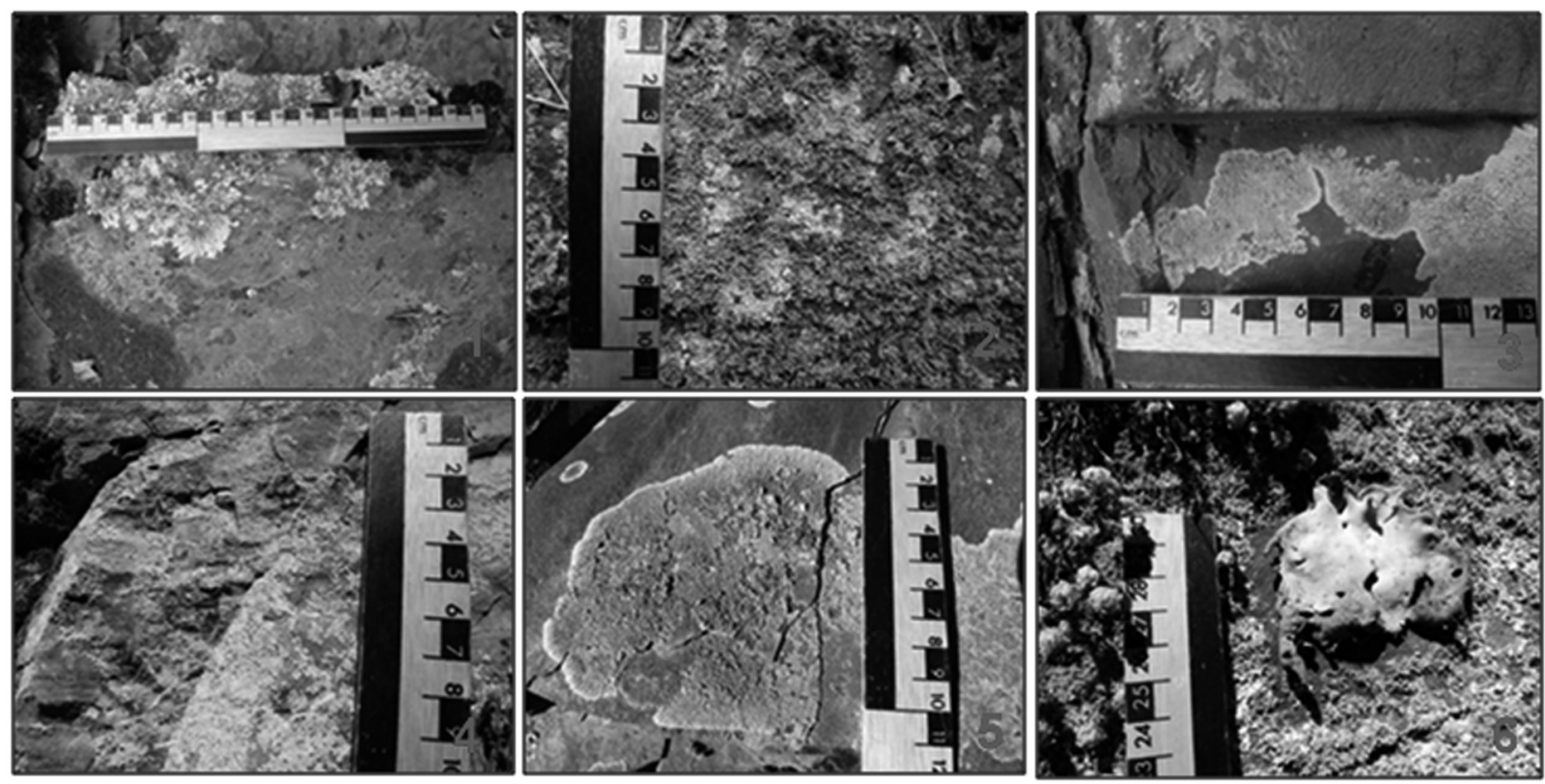

Fig. 18. Liquenes identificados en el panel con arte rupestre: 1) Parmelia sp. y Xanthoparmelia sp.; 2) Chrisoteix sp.; 3) Candelariella $s p$.; 4) Candelariella $s p . y$ Rizocarpun geographicum; 5) Lecanora muralis; 6) Lasallia pustulata.

fueron realizadas las figuras, del sustrato rocoso sobre el que fueron pintadas, de las concreciones detectadas superpuestas a los motivos pintados y de óxidos naturales procedentes del entorno del abrigo.

- Pigmento: se obtuvo de los motivos realizados sobre una placa desprendida de forma natural $(\approx 11 \mathrm{~cm}$ de anchura máxima $\mathrm{x} 4,5 \mathrm{~cm}$ de longitud) en buen estado de conservación (muestra de pigmento analizada directamente sobre el soporte natural).

- Sustrato: constituye el soporte rocoso sobre el que fueron efectuadas las pinturas y las muestras analizadas también se obtuvieron del fragmento desprendido objeto de estudio.

- Concreciones: hacen referencia a las concreciones de materiales diversos que cubren en diversas zonas las pinturas en los paneles rocosos decorados, la mayor parte de las ocasiones asociados con nidos de aves.

- Óxidos naturales: se recogieron diversas muestras del entorno con el propósito de determinar a través de su análisis la posible procedencia de las materias primas empleadas en la elaboración del pigmento.
Respecto a la biocolonización del abrigo, no se recogieron muestras de líquenes, procediendo en este sentido únicamente a la documentación in situ mediante registro fotográfico y microscopio portátil (Microscopio Digitale usb 220X o 400X) de las colonias detectadas en el abrigo, que posteriormente fueron identificadas en el laboratorio por Luis Santos (microbiólogo del Instituto Politécnico de Tomar, Portugal) mediante la comparación en bases de datos on-line (http://www.uv.es/barreno/; www. uklichens.co.uk; y www.msu.edu).

De este modo, los líquenes identificados pertenecen mayoritariamente al grupo de los líquenes crustosos (Fig. 18, n. ${ }^{\text {os }} 1,3-5$ ); igualmente se ha identificado un grupo de líquenes foliosos (Fig. 18, n. ${ }^{\circ}$ 6) y otro de líquenes tipo 'pólvora' o Chrisoteix (Fig. 18, n. ${ }^{\circ}$ 2). Debemos reseñar que los líquenes crustosos son aquellos cuyo talo se desarrolla en mayor profundidad, de modo que resulta prácticamente imposible separar el liquen del soporte sin destruir este, y resultan, en consecuencia, los más agresivos con respecto al sustrato y los pigmentos sobre los que se instalan ya que, además, las características del talo de este tipo de líquenes les permite sobrevivir en ambientes muy extremos y en superficies expuestas de la roca. 
Metodológicamente, como ya se ha apuntado, los análisis realizados para el presente estudio incluyeron la espectroscopia Raman, la microfluorescencia-x y la microestratigrafía, siendo efectuados con el siguiente material:

- Espectroscopia Raman: las muestras fueron analizadas con un Jobin Yvon Raman Explorer Spectramax, HeNe láser, número de onda de $632,83 \mathrm{~nm}$. Los espectros de las muestras se obtuvieron usando un microscopio BXFM Olympus acoplado con un espectrómetro Labram hr800 (Horiba Jobin Yvon, Francia), provisto de un detector CCD refrigerado por aire (1024 x 256 píxeles), puesta a $-70{ }^{\circ} \mathrm{C}$. El espectrómetro tenía una longitud focal de $80 \mathrm{~mm}$ y estaba equipado con sendas rejillas de 600 y 1800 surcos $/ \mathrm{mm}$. Se registraron espectros Raman utilizando un He-Ne láser como fuente de excitación, con longitud de onda de 632,81 nm. El diámetro del láser era de aproximadamente $1 \mathrm{~mm}$ y la resolución del espectrómetro de aproximadamente $4 \mathrm{~cm}^{-1}$. La potencia del láser se mantuvo constante, entre 0,2 y $4 \mathrm{~mW}$, y el tiempo de exposición varió entre 5 y $10 \mathrm{~s}$ con 10 acumulaciones. El espectrómetro se calibró con silicio a $520 \mathrm{~cm}^{-1}$. La eliminación de picos de los rayos cósmicos y la corrección de la línea de base (para la sustracción del fondo de fluorescencia) se realizaron utilizando el software LabSpec 5, y la identificación de los picos desconocidos fue obtenida mediante comparación con bases de datos (www.Ruff.org; http://www.mindat. org/) y a través de la bibliografía disponible.

- Microfluorescencia de rayos $X(\mu \mathrm{FRX})$ : se usó un espectrómetro EDXRF (Bruker-Artax- Element Analysis; método: Standard_15kV [Bayes]; óptica: Colimador $200 \mu \mathrm{m}$; intensidad de $40 \mu \AA$, $25 \mathrm{kV}$, tiempo de adquisición de 50 segundos, calibrado con el $\mathrm{Cu}$ ). El espectro fue leído usando un programa Amptek. Debe tenerse en cuenta que este dispositivo solo permite la detección de elementos químicos con números atómicos $>20(\mathrm{Ca})$.

- Microestratigrafía: las muestras fueron preparadas y analizadas con un microscopio óptiCO PCE -microscopio digital MM 200 a 60 x y 210 x aumentos-.

\begin{tabular}{|c|c|c|}
\hline Muestra & Descripción & Resultado analítica \\
\hline Mon. & Pigmento rojo & Hematita $(\alpha$-Fe2O3) \\
\hline
\end{tabular}

Fig. 19. Tabla con resultados del análisis del pigmento con espectroscopia Raman.

El resultado obtenido en los diferentes procesos analíticos se expone a continuación:

\subsection{Espectroscopia Raman}

El análisis mineralógico desarrollado (Fig. 19) en la muestra de pigmento (MON) reveló esencialmente óxidos de hierro (hematita $-\alpha-\mathrm{Fe}_{2} \mathrm{O}_{3}$ ) con bandas Raman a 220, 241, 289, 407, 491, 609, y $1315 \mathrm{~cm}^{-1}$ atribuible a la hematita (Fig. 20).

De acuerdo con la espectroscopia micro-Raman, los pigmentos rojos se presentan como colorantes heterogéneos, comprendiendo una matriz con puntos rojos y negros dispersos.

Teniendo en cuenta que el láser altera drásticamente la estructura de los probables óxidos de hierro de los pigmentos (Shebanova y Lazor, 2003; El Mendili et al., 2011), su potencia fue reducida hasta un grado de $0,2 \mathrm{~mW}$, con $30 \mathrm{~s}$ de tiempo de exposición.

Las bandas Raman de los diversos tipos de óxidos de hierro son recogidas de forma bastante ambigua en la bibliografía especializada, de modo que diferentes bandas pueden aparecer relacionadas con una determinada variante de óxido férrico (Faria $e t$ al., 1997; Clark y Curri, 1998; Cornell y Schwertmann, 2003; Shebanova y Lazor, 2003; Hanesch, 2009). Estas variaciones pueden responder al empleo de diferentes potencias de láser en la obtención de los espectros de dichos óxidos, pues la aplicación de potencias inadecuadas puede provocar las alteraciones de las fases minerales, si bien los picos o bandas características de cada fase mineral de óxido de hierro, ya sean férricas, ferrosas o mixtas, resultan independientes del tipo de láser que se use.

Los espectros de los puntos rojos demostraron la presencia de hematita (Fig. 20). Una banda identificada en torno a $665 \mathrm{~cm}^{-1}$ (Hanesch, 2009) podría ser atribuida a la magnetita (Faria et al., 1997; Clark y Curri, 1998; Cornell y Schwertmann, 2003; Shebanova y Lazor, 2003; Hanesch, 2009). Las hematitas naturales pueden contener 


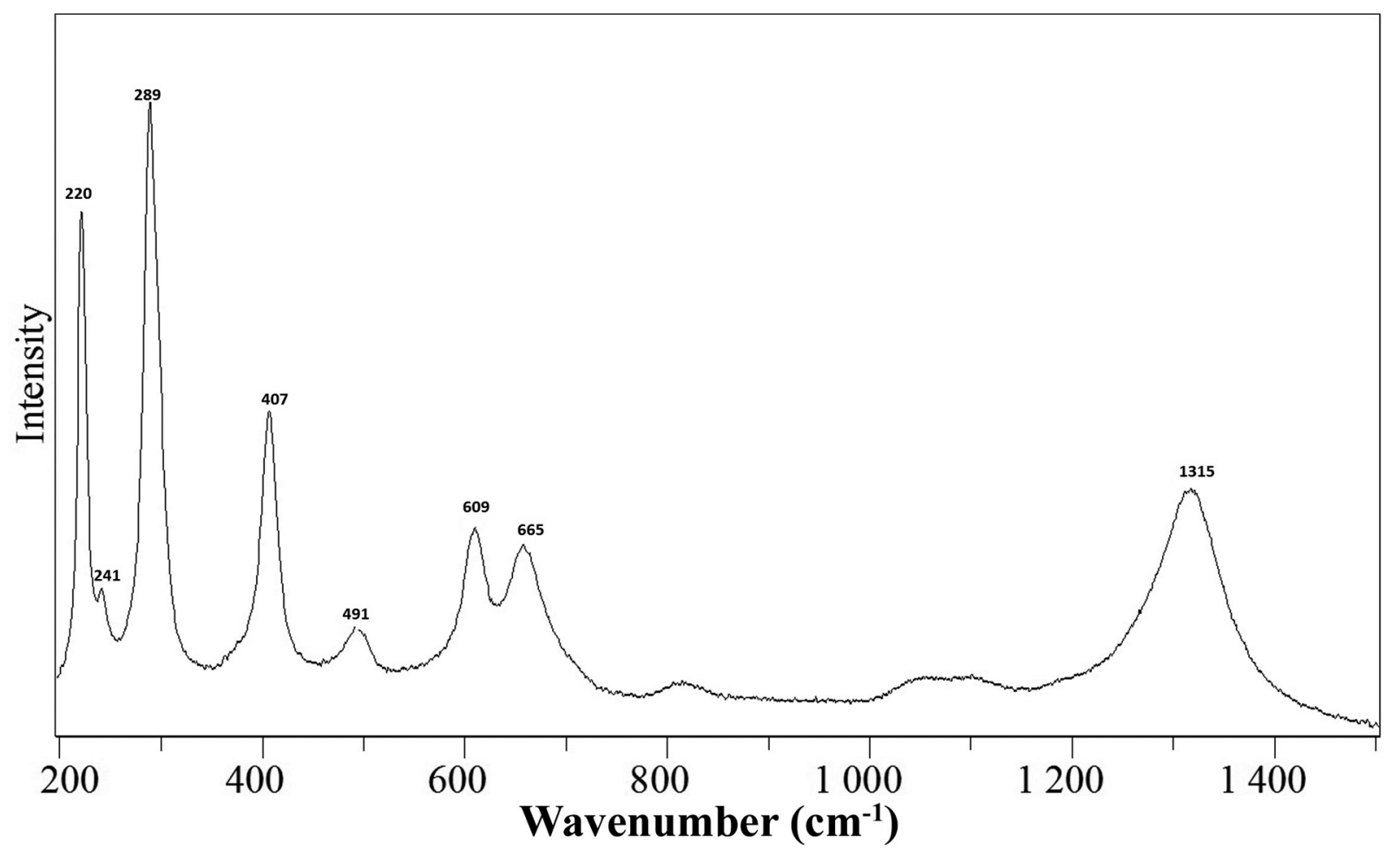

FIG. 20. Espectro del pigmento obtenido mediante espectrometria Raman.

dicha banda o muy próxima a ella; esta misma banda puede también ser atribuida a la maghemita $\left(381,486\right.$ y $\left.710 \mathrm{~cm}^{-1}\right)$, si bien este mineral no fue observado en la muestra (Cornell y Schwermann, 2003; Hanesch, 2009; Legodi y Waal, 2007: 161168). La magnetita se transforma rápidamente en $\alpha-\mathrm{Fe} 2 \mathrm{O} 3$ (hematita) debido al efecto del láser (Bell et al., 1997). Otra banda Raman de la magnetita situada en torno a $540 \mathrm{~cm}^{-1}$ (Hanesch, 2009), que resulta habitual en la literatura especializada, no fue, sin embargo, detectada en este caso, probablemente debido a la baja potencia del láser. Otras bandas Raman a 220, 283, 400 y $615 \mathrm{~cm}^{-1}$ pueden ser atribuidas a la hematita (Faria y otros, 1997; Clark y Curri, 1998; Cornell y Schwertmann, 2003; Hanesch, 2009) y relacionadas con las variaciones de las diferentes aplicaciones del láser. Finalmente, las bandas 1303 y $1597 \mathrm{~cm}^{-1}( \pm 1600$ $\mathrm{cm}^{-1}$ ) detectadas en los puntos negros (también observables en el Raman y en la microestratigrafía) del pigmento rojo (Fig. 22), pueden ser atribuibles a la presencia de carbón (Hanesch, 2009).
La técnica utilizada raramente permite la identificación de las arcillas, uno de los componentes frecuentemente utilizados para mejorar las cualidades de los pigmentos rojos, aunque, en nuestro caso, ni arcillas ni aglutinantes han sido identificados, debiendo aclarar que esta carencia puede ser debida a las limitaciones de los aparatos utilizados en el proceso de análisis -salvo que se haga uso de SERS (Surface-enhanced Raman Spectroscopy)-, si bien en esta ocasión la principal dificultad en cuanto a la determinación del aglutinante se debe a la más que probable degradación del mismo o a su baja concentración.

En cualquier caso, queda determinado que para la elaboración del pigmento rojo de este abrigo fue utilizada la hematita, como, por otra parte, resulta común en la elaboración de pigmentos prehistóricos que han sido analizados en la Península Ibérica, con presencia sistemática de óxidos e hidróxidos de hierro (Hernanz et al., 2010; Pike et al., 2012). Estos elementos cromófobos son asociados con otras sustancias minerales (siendo las arcillas las más 


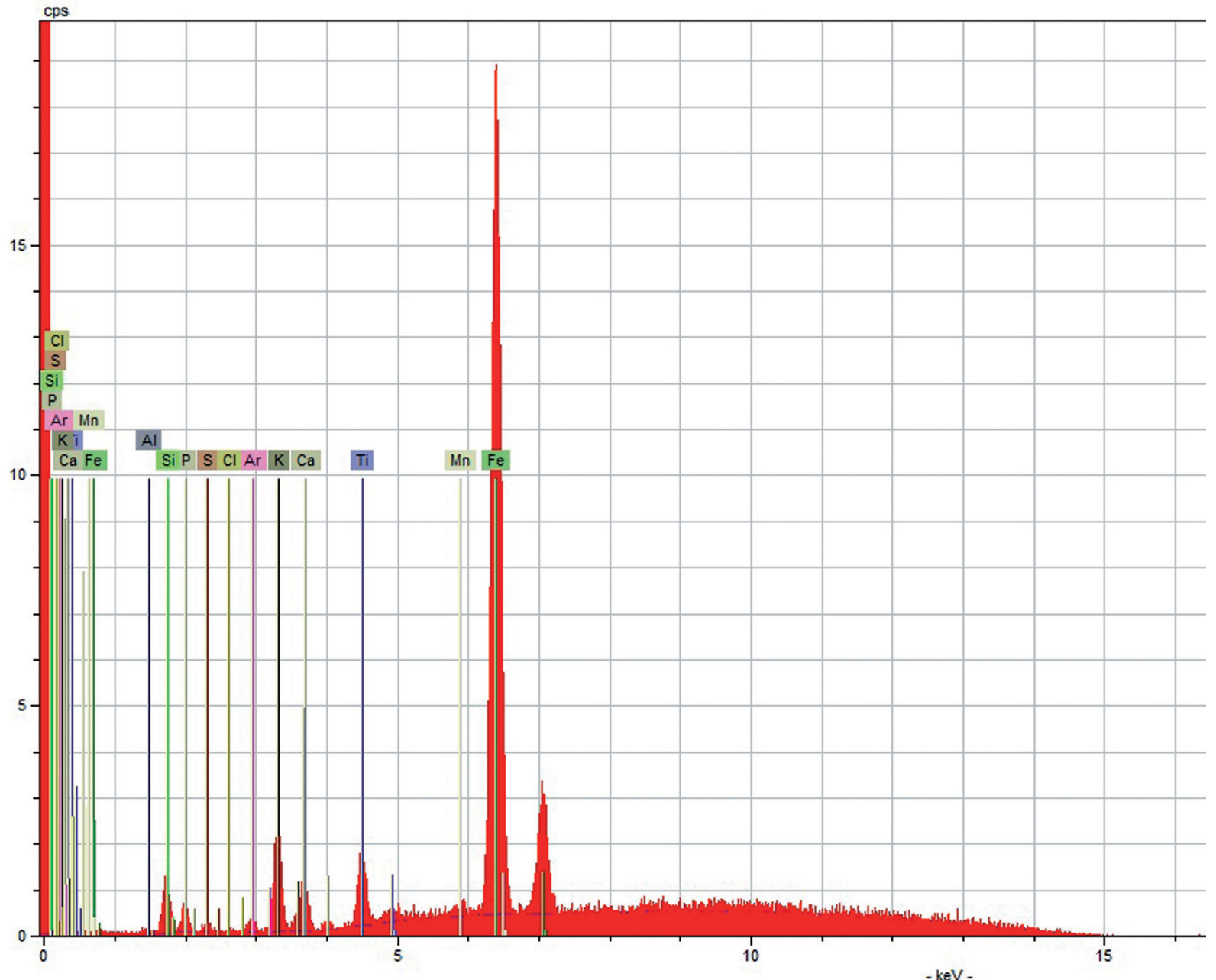

FIG. 21. Espectro del pigmento obtenido mediante microfluorescencia de rayos $X$.

comunes), dando lugar al ocre, con tendencias hacia tonalidades amarillas cuando contienen goethita, $\mathrm{o}$ al rojo cuando en su composición interviene mayoritariamente la hematita (Iriarte et al., 2009). En esta línea son abundantes y variados los estudios publicados referentes al tratamiento de los ocres, especialmente en pinturas prehistóricas, relativos a su aplicación y a la mejoría de su coloración mediante tratamientos que implican su calentamiento, determinados mediante la aplicación de diversas técnicas, como los análisis termales, la espectroscopia FT-IR, los análisis magnéticos y voltamperemétricos, la difracción de los rayos x (Mazzocchin et al.,
2003; Pomies et al., 1999; Clarke et al., 1998) o la propia espectroscopia Raman (Clarke et al., 1998; Edwards et al., 2000; Ospitali et al., 2006).

\subsection{Microfluorescencia de rayos $X$}

El análisis de la muestra de pigmento reveló que el elemento químico predominante (con un número atómico superior a 20) es, como era de esperar, el hierro, con una significativa presencia de titanio y, en una menor proporción, manganeso, estroncio y elementos menores (Fig. 21). 


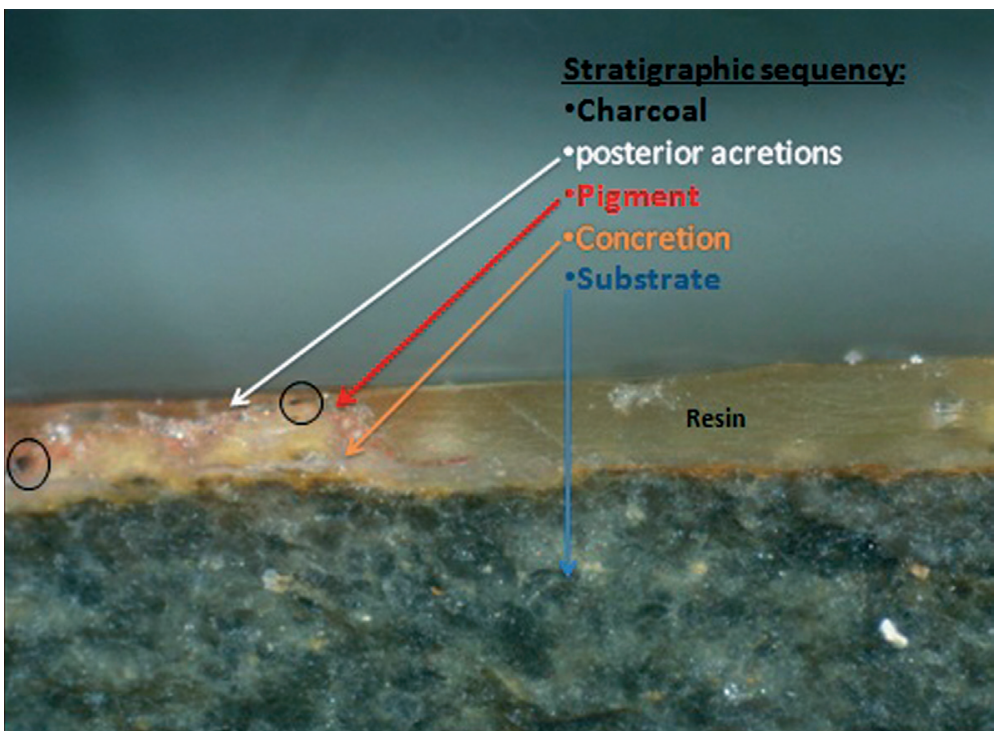

FIG. 22. Microestratigrafia de la muestra de pigmento obtenida en las pinturas del Friso del Terror.

\subsection{Microestratigrafía}

La observación de la sección transversal de los estratos microestratigráficos de las muestras analizadas reveló el orden posicional de los tres elementos principales que la componen (roca, concreción, pintura) de grosor variable.

Sobre la roca cuarcítica de base, se desarrolló un fino depósito de concreciones de un grosor aproximado de $0,19 \mathrm{~mm}$ sobre el que posteriormente se aplicó el pigmento rojo detectado con espesores variables de aproximadamente $0,045 \mathrm{~mm}$ y un diferente grado de absorción o penetración sobre el estrato que le precede, lo que provoca que en ocasiones las huellas de los elementos colorantes no sean visibles en absoluto. Finalmente esta capa de pigmento fue nuevamente cubierta por concreciones y acreciones (Fig. 22). Algunos productos de alteración se encuentran también presentes, posiblemente oxalatos y fosfatos derivados de la acción biológica de los líquenes y de la mineralización del guano de las aves (Frost, 2004; Clarke y Williams, 1986).

Intercaladas en la estratigrafía se observaron diminutas manchas oscuras y otros elementos en asociación con los componentes de la pintura. Su análisis posterior determinó que se trataba, por una parte, de residuos de carbón y, por otra, óxidos de manganeso (Mn) (Fig. 22).
Las partículas de carbón vegetal se caracterizan por su tamaño no estándar; la forma y su distribución y origen parecen ser independientes de la pintura, mientras que los óxidos aparecen más "organizados" y redondos; algunos de ellos, incluso, parecen estar incorporados en la concreción.

\section{Consideraciones finales}

Las analíticas que acabamos de describir realizadas sobre los pigmentos del Friso del Terror determinan, una vez más, el empleo de hematites en la elaboración de los pigmentos con los que se dibujaron las pinturas rupestres. En este sentido, su uso en este abrigo reitera el ya detectado en los análisis realizados sobre los pigmentos utilizados en las representaciones de la Cueva del Castillo de Monfragüe $e^{5}$ Se trata de un mineral relativamente abundante en el área del parque, y que ha podido ser detectado en las proximidades de ambas estaciones rupestres, por lo que es posible considerar que los autores que realizaron las figuras esquemáticas de este espacio, conocedores del territorio por el que desarrollaban su actividad, se aprovisionaran del material necesario para hacer las pinturas en las cercanías de la estación pictórica.

Los productos de alteración biológica están presentes en toda la superficie de la muestra, y se encuentran representados por elementos diferentes relativos a diversos procesos naturales (por ejemplo, la actividad de los líquenes o la mineralización del guano) (Frost, 2004).

Lamentablemente los aglutinantes, y especialmente los orgánicos, no han podido ser identificados en ningún caso. La única materia orgánica reconocida fue el carbón, que también fue identificado en las pinturas de la Cueva del Castillo, si bien el análisis microestratigráfico reveló que no constituye un componente propio del pigmento, y su presencia debe entenderse como una consecuencia

5 Estos análisis fueron realizados por Artelab S.R.L. (Roma, Italia), en el marco de los trabajos de limpieza de las pinturas rupestres de la Cueva del Castillo de Monfragüe, bajo la dirección de E. Guillamet y L. Ballester. 
de las frecuentaciones posteriores de estos enclaves por grupos humanos, aunque sin descartar tampoco un origen natural como los incendios fortuitos, tan habituales en estas áreas de tupida vegetación, y que podrían haber provocado impregnaciones de partículas de carbón sobre los paneles decorados.

Por otra parte, gracias al sondeo operado en la Cueva del Sapo, situada a apenas unos $500 \mathrm{~m}$ del Friso del Terror aguas arriba del Arroyo Barbaón, se ha documentado por vez primera en el espacio del Parque Nacional de Monfragüe un asentamiento prehistórico relacionado físicamente con un abrigo con arte rupestre. Obviamente, como ya se ha puntualizado, resulta problemático establecer a priori una correspondencia directa y unívoca entre la ocupación humana de este covacho y la elaboración de las pinturas rupestres que se conservan en sus paredes, aunque tampoco descartamos esa posibilidad. Y fundamentamos esta última propuesta en una doble premisa: en primer lugar, si tenemos en cuenta el procedimiento de elaboración de los propios pigmentos con los que se realizaron los pictogramas, en el cual, como acabamos de ver, se emplearon materiales procedentes del entorno inmediato a los abrigos, y cuya disponibilidad debía sin duda ser bien conocida por las gentes que cotidianamente se desplazaban por estos parajes aprovechando y explotando sus recursos; y, en segundo lugar, si consideramos que serían estos mismos grupos humanos los posibles responsables de unas estrategias de control del territorio en las que, como parte integrante de su actividad, procederían a la marcación simbólica del paisaje a través de un código pictográfico plasmado en abrigos y paredes fácilmente visualizables por potenciales visitantes. Como hemos argumentado en los apartados precedentes, tal apropiación gráfico-simbólica del entorno probablemente no tendría tanto una finalidad de carácter religioso o ritual -como tantas veces se ha venido indicando para las rocas decoradas-, sino una funcionalidad más marcadamente económica, dirigida a la señalización, capitalización y explotación de los recursos naturales y de las rutas de comunicación que, como el cañón del Arroyo Barbaón, permiten la transitabilidad a través de este agreste enclave.

Quedamos a la espera de futuros hallazgos en la misma zona que nos permitan corroborar con mayor solvencia la posible conexión entre aquellos habitantes prehistóricos y las abundantes grafías persistentes en sus roquedos, y que nos permitan afianzar y ajustar con mayor precisión la cronología de este notable complejo de manifestaciones artísticas.

\section{Bibliografía}

BADER, M. (2006): "Organización territorial, funcionalidad y significación del arte rupestre de la Prehistoria reciente de la Península Ibérica”. En Martínez García, J. y Hernández Pérez, M. S. (eds.): Actas del Congreso de Arte Rupestre Esquemático en la Peninsula Ibérica: Comarca de los Vélez, 2004. Almería, pp. 195-209.

BelL, I. M.; Clark, R. J. H. y Gibbs, P. J. (1997): "Raman Spectroscopic Library of Natural and Synthetic Pigments (pre-1850 AD)", Spectrochimica Acta, part A, 53, pp. 2159-2179.

http://dx.doi.org/10.1016/S1386-1425(97)00140-6

Bradley, R. y Fabregas, R. (1999): "La 'ley de la frontera': grupos rupestres galaico y esquemático y Prehistoria del noroeste de la Península Ibérica", Trabajos de Prehistoria, 56 (1), pp. 103-114. http://dx.doi.org/10.3989/tp.1999.v56.i1.292

Clark, R. J. H. y Curri, M. L. (1998): "The identification by Raman Microscopy and x-ray Diffraction of Iron-Oxide Pigments and of the Red Pigments Found on Italian Pottery Fragments", Journal of Molecular Structure, 440, pp. 105-111. http://dx.doi.org/10.1016/S0022-2860(97)00239-1

Clarke, R. H.; Londhe, S. y Womble, M. E. (1998): "Low-Resolution Raman Spectroscopy as an Analytical Tool for Organic Liquids", Spectroscopy, 13, pp. 28-35.

Clarke, R. M. y Williams, I. R. (1986): "Moolooite, a Naturally Occurring Hydrated Copper Oxalate from Western Australia”, Mineralogical Magazine, 50, pp. 295-298.

http://dx.doi.org/10.1180/minmag.1986.050.356.15

Collado, H. (1997): "Arte rupestre esquemático en la provincia de Badajoz. Cuestiones tipológicas, interpretativas y cronológicas". En Extremadura Arqueológica, VII, pp. 158-171.

Collado, H. (2009): "Propuesta para la clasificación funcional y cronológica del arte rupestre esquemático a partir del modelo extremeño". En CRUZ-AUNón, R. y Ferrer, E. (coords.): Estudios de Prehistoria y Arqueología en homenaje a P. Acosta Martinez. Sevilla: Univ. de Sevilla, pp. 89-108.

Collado, H.; Fernández Algaba, M.; Pozuelo, D. y Girón, M. (1997): "Pinturas rupestres esquemáticas 
en la transición del iv al III milenio a.C. El abrigo de la Charneca Chica (Oliva de Mérida, Badajoz)", Trabajos de Prehistoria, 54 (2), pp. 143-149. http://dx.doi.org/10.3989/tp.1997.v54.i2.371

Collado, H. y García Arranz, J. J. (2001): “El Parque Natural de Monfragüe. La mayor concentración de pintura esquemática en Extremadura”. En Actas del Congreso Internacional de Arte Rupestre Europea. Vigo: Concello de Vigo (edición en CD).

Collado, H. y García Arranz, J. J. (coords.) (2005): Arte rupestre en el Parque Natural de Monfragüe: El Sector Oriental. Corpus de Arte Rupestre en Extremadura, vol. I. Mérida: Junta de Extremadura.

Collado, H. y García Arranz, J. J. (2007): "Últimas intervenciones en la Cueva del Castillo de Monfragüe (Cáceres): actuaciones de adecuación para la visita y revisión de sus manifestaciones rupestres". Cuadernos de Arte Rupestre, 4, pp. 313-351.

Collado, H. y García Arranz, J. J. (2010): “10000 ańos de arte rupestre. El ciclo preesquemático de la Península Ibérica y su reflejo en Extremadura (España)". En Actas del Congreso IFRAO 2009. Parque Nacional de la Sierra de Capivara (Piaui, Brasil). Fumdhamentos, IX, vol. IV, sesión 23, pp. 1167-1192.

Collado, H.; García Arranz, J. J.; Da Silva, L. F.; Domínguez García, I. M.a; Rivera, E.; Nacarino, M. y Capilla, J. E. (2011): "Organização do Território a través da Arte Rupestre: o exemplo do Arroyo Barbaón no Parque Nacional de Monfragüe (Cáceres, Espanha)", Arkeos. Perspectivas em diálogo (n. ${ }^{\circ}$ especial Landscape within Rock Art), 29, pp. 43-57.

Cornell, R. M. y Schwertmann, U. (2003): The Iron Oxides-Structure, Properties, Reactions, Occurrences and Uses. Weinheim: Wiley-vch Verlag.

Cristini, O.; Kinowski, C. y Turrell, S. (2010): "A Detailed Micro-Raman Spectroscopic Study of Wall Paintings of the Period AD 100-200: Effect of Atmospheric Conditions on the Alteration of Samples", Journal of Raman Spectroscopy, 41, pp. 1410-1417. http://dx.doi.org/10.1002/jrs.2656

Edwards, H. G. M.; Newton, E. M. y Russ, J. (2000): "Raman Spectroscopic Analysis of Pigments and Substrata in Prehistoric Rock Art", Journal of Molecular Structure, 550-1, pp. 245-256. http://dx.doi.org/10.1016/S0022-2860(00)00389-6

El Mendili, Y.; Bardeau, J.-F.; Randrianantoandro, N.; Gourbil, A.; Greneche, J. M.; Mercier, A. M. y Grasset, F. (2011): "New Evidences of In Situ Laser Irradiation Effects on $\gamma$-Fe2O3 Nanoparticles: a Raman Spectroscopic Study", Journal of Raman Spectroscopy, 42, pp. 239-242. http://dx.doi.org/10.1002/jrs.2762

FAIRÉN, S. (2006): "Nuevas herramientas para el análisis de la distribución de la pintura rupestre esquemática: el ejemplo de las comarcas centro-meridionales valencianas". En Martínez García, J. y Hernández Pérez, M. S. (eds.): Actas del Congreso de Arte Rupestre Esquemático en la Peninsula Ibérica: Comarca de los Vélez, 2004. Almería, pp. 211-222.

Faria, D. L. A.; Venâncio Silva, S. y Oliveira, M. T. (1997): "Raman Microspectroscopy of Some Iron Oxides and Oxyhydroxides", Journal of Raman Spectroscopy, 28 (11), pp. 873-878.

http://dx.doi.org/10.1002/(SICI)1097-4555(199711)

28:11<873::AID-JRS177>3.3.CO;2-2

http://dx.doi.org/10.1002/(SICI)1097-4555(199711) 28:11<873::AID-JRS177>3.0.CO;2-B

Frost, R. L. (2004): "Raman Spectroscopy of Natural Oxalates", Analytica Chimica Acta, 517 (1-2), pp. 207-214.

http://dx.doi.org/10.1016/j.aca.2004.04.036

García ARranz, J. J. (1990): La pintura rupestre esquemática en la comarca de Las Villuercas (Cáceres). Salamanca: Diput. Prov. de Cáceres.

García Arranz, J. J. (1997): "La pintura rupestre esquemática en la provincia de Cáceres". En Extremadura Arqueológica, vII, pp. 119-140.

Gumiel, P.; Campos, R.; Segura, M. y Monteserín, V. (2008): Guía Geológica del Parque Natural de Monfragüe. Badajoz: Junta de Extremadura.

Hanesch, M. (2009): "Raman Spectroscopy of Iron Oxides and (Oxy)Hydroxides at Low Laser Power and Possible Applications in Environmental Magnetic Studies", Geophysical Journal International, 177, pp. 941-948.

http://dx.doi.org/10.1111/j.1365-246X.2009.04122.x

Hernanz, A.; Gavira-Vallejo, J. M. y Ruiz-López, J. F. (2007): "Calcium Oxalates and Prehistoric Paintings. The Usefulness of these Biomaterials", Journal of Optoelectronics and Advanced Materials, 9 (3), pp. 512-521.

Hernanz, A.; Ruiz-López, J. F.; Gavira-Vallejo, J. M.; Martín, S. y Gavrilenko, E. (2010): "Raman Microscopy of Prehistoric Rock Paintings from the Hoz de Vicente, Minglanilla, Cuenca, Spain”, Journal of Raman Spectroscopy, 41 (11), pp. 1394-1399. http://dx.doi.org/10.1002/jrs.2582

Hradil, D.; Grygar, T.; Hradilová, J. y BezdičKa, P. (2003): "Clay and Iron Oxide Pigments in the History of Painting", Applied Clay Science, 22 (5), pp. 223-236.

http://dx.doi.org/10.1016/S0169-1317(03)00076-0

Iriarte, E.; Foyo, A.; Sánchez, M. A. y Setién, J. (2009): "The Origin and Geochemical Characterization of Red Ochres from the Tito Bustillo and Monte Castillo Caves (Northern Spain)", Archaeometry, 51 (2), pp. 231-251. http://dx.doi.org/10.1111/j.1475-4754.2008.00397.x 
Leco, F.; Pérez, A.; Mateos, B.; Alvarado, E.; Rodríguez, Á. e Iglesias, C. (2009): Reserva Mundial de la Biosfera de Monfragüe. Aproximación geográfica y visión cartográfica. Badajoz: Univ. de Extremadura.

Legodi, M. A. y WaAl, D. (2007): "The Preparation of Magnetite, Goethite, Hematite and Maghemite of Pigment Quality from Mill Scale Iron Waste", Dyes and Pigments, 74, pp. 161-168.

http://dx.doi.org/10.1016/j.dyepig.2006.01.038

Martínez García, J. (1998): “Abrigos y accidentes geográficos como categorías de análisis en el paisaje de la pintura rupestre esquemática. El sudeste como marco", Arqueología Espacial, 19-20 (n. ${ }^{\circ}$ especial "Arqueología del Paisaje"), pp. 543-561.

Mateo Saura, M. Á. (2003): Arte rupestre prehistórico en Albacete. La cuenca del río Zumeta (serie Estudios, n. ${ }^{\circ}$ 147). Albacete: Diput. Prov. de Albacete.

Mazzocchin, G. A.; Agnoli, F.; Mazzocchin, S. y Colpo, I. (2003): "Analysis of Pigments from Roman Wall Paintings Found in Vicenza", Talanta, 61/4, pp. 565-572.

http://dx.doi.org/10.1016/S0039-9140(03)00323-0

Ospitali, F.; Smith, D. y Lorblanchet, M. (2006):

"Preliminary Investigations by Raman Microscopy of Prehistoric Pigments in the Wall-Painted Cave at Roucadour, Quercy, France", Journal of Raman Spectroscopy, 37, pp. 1063-1071. http://dx.doi.org/10.1002/jrs.1611

Pike, A. W. G.; Hoffmann, D. L.; García-Díez, M.; Pettitt, P. B.; Alcolea, J.; De Balbín, R.; González-Sainz, C.; De las Heras, C.; Lasheras, J. A.; Montes, R. y Zilhấo, J. (2012): “U-Series
Dating of Paleolithic Art in 11 Caves in Spain”, Science, vol. 336, n. ${ }^{\circ}$ 6087, pp. 1409-1413.

Pomies, M. P.; Barbaza, M.; Menu, M. y Vignaud, C. (1999): "Préparation des pigments rouges préhistoriques par chauffage", L'Anthropologie, 103 (4), pp. 503-518.

Prisloo, L. C.; Barnard, W.; Meiklejohn, I. y Hall, K. (2008): "The first Raman Spectroscopic Study of San Rock Art in the Ukhahlamba Drakensberg Park, South Africa”, Journal of Raman Spectroscopy, 39, pp. 646-654. http://dx.doi.org/10.1002/jrs.1901

Shebanova, O. N. y Lazor, P. (2003): "Raman Study of Magnetite (Fe3O4): Laser-Induced Thermal Effects and Oxidation", Journal of Raman Spectroscopy, 34, pp. 845-852. http://dx.doi.org/10.1002/jrs.1056

Smith, G. D. y Clark, R. J. H. (2004): "Raman Microscopy in Archaeological Science", Journal of Archaeological Science, 31, pp. 1137-1160. http://dx.doi.org/10.1016/j.jas.2004.02.008

Torregrosa, P. (2000-2001): "Pintura rupestre esquemática y territorio: análisis de su distribución espacial en el levante peninsular", Lucentum, XIX-Xx, pp. 39-65.

Utrilla, M. a P. y Martínez Bea, M. (2009): “Acerca del arte esquemático en Aragón. Terminología, superposiciones y algunos paralelos mobiliares". En Cruz-Auñón, R. y Ferrer, E. (coords.): Estudios de Prehistoria y Arqueología en homenaje a P. Acosta Martinez. Sevilla: Univ. de Sevilla, pp. 109-140. 